\title{
29 \\ PC Software for Optimizing Groundwater Contaminant Plume Capture and Containment
}

\author{
Richard C. Peralta, Herminio H. Suguino, and Alaa H. Aly \\ Utah State University \\ Logan, Utah
}

\section{INTRODUCTION}

Simulation/optimization $(\mathrm{S} / \mathrm{O})$ models can be used to speed the process of computing desirable groundwater pumping strategies for plume management. They make the process of computing optimal strategies fairly straightforward and can help minimize the labor and cost of groundwater contaminant cleanup.

Differences between S/O models and the simulation (S) models currently used by over $98 \%$ of practitioners are discussed in Section II [1], followed by an overview of the two most common forms of groundwater management $S / O$ models, their strengths and limitations, in Section III. In Section IV, currently available PC-based S/O models are discussed, and the ways in which they would be applied to representative situations are illustrated. Included is US/ WELLS ${ }^{D}$, an easy-to-use deterministic model that requires minimal data but will address aquifer and stream-aquifer systems where the analytical solutions of Theis [2] and Glover and Balmer [3] are appropriate. Also included is US/REMAX ${ }^{\mathrm{B}}$, appropriate for heterogeneous, multilayer systems. To ease use, that code accepts data in format readable by MODFLOW [4], the most widely used flow simuiation model in the United States today.

These two S/O models are selected because they are the only ones we are aware of that (1) are available for use on PCs, (2) include with them the optimization algorithms necessary for solution, and (3) use superposition. As explained later, these characteristics make them especially useful for plume management by consultants and water resource managers.

\section{COMPARISON BETWEEN COMMONLY USED SIMULATION MODELS AND SIMULATION/OPTIMIZATION MODELS}

A simulation/optimization (S/O) model contains both simulation equations and an operations research optimization algorithm. The simulation equations permit the model to appropriately represent aquifer response to hydraulic stimuli and boundary conditions. The optimization al- 
gorithm permits the specified management objective to serve as the function driving the search for an optimal strategy. The model computes a pumping strategy that minimizes (or maximizes) the value of the objective function.

Table 1 shows generic inputs and outputs of the generally used simulation (S) model and those of an S/O model. The normal $S$ models compute aquifer responses to assumed (input) boundary conditions and pumping values. Using such models to develop acceptable pumping strategies can be tedious and involve much trial and error. For example, simulated system responsc to an assumed pumping strategy might cause unacceptable consequences. In that case, the user must assume another pumping strategy, reuse the model to calculate aquifer response, and recheck for acceptability of results. This process of assuming, predicting, and checking might have to be repeated many times. The number of repetitions increases with the number of pumping locations and control locations (places where acceptability of system response must be evaluated and ensured).

When using an $\mathrm{S}$ model, as the number of possible pumping sites increases the likelihood that the user has assumed an "optimal" strategy decreases. Also, as the number of restrictions on acceptable system response to pumping increases, the ability of the user to assume an optimal strategy also decreases. Assuming a truly optimal strategy becomes impractical or nearly impossible as problem complexity increases. There are too many different possible combinations of pumping values. Furthermore, even if the computation process is automated in a computer program, the act of checking and ensuring strategy acceptability becomes increasingly painful as the number of control locations becomes large. In essence, it becomes impossible to compute mathematically optimal strategies for complicated groundwater management problems using $\mathrm{S}$ models.

Alternatively, S/O models directly calculate the best pumping strategies for the specified management objectives and ensure that the resulting heads and flows lie within prespecified limits or bounds (Table 1). The upper and lower bounds reflect the range of values that the user considers acceptable for cell pumping rates and resulting heads. The model automatically considers the bounds while calculating optimal pumping strategies. The user might choose to use lower bounds on pumping at currently operating public supply wells. He/she might choose to limit pumping at the upper end of the range, depending on hardware availability or legal restrictions. The user might impose lower bounds on head, at a specific distance below current water levels or above the base of the aquifer. Upper bounds might be the ground surface or a specified distance below the ground surface.

Assume, for example, a situation in which a planning agency is attempting to determine the least amount of groundwater pumping needed to capture a contaminant plume and the locations where it should be pumped, i.e., the spatial distribution of the withdrawals and injections. If a pumping strategy is not implemented to achieve capture, the contaminant will reach public supply wells, resulting in litigation and undesirable costs.

Table 1 Comparison Between Simulation and Simulation/Optimization Models

\begin{tabular}{lll}
\hline Model type & \multicolumn{1}{c}{ Input values } & \multicolumn{1}{c}{ Computed values } \\
\hline Simulation (S) & $\begin{array}{l}\text { Some boundary flows } \\
\text { Some boundary heads } \\
\text { Pum̌ping }\end{array}$ & $\begin{array}{l}\text { Some boundary flows } \\
\text { Heads at "variable" head cells }\end{array}$ \\
Simulation/optimization $(\mathrm{S} / \mathrm{O})$ & $\begin{array}{l}\text { Some boundary flows } \\
\text { Some boundary heads } \\
\text { Bounds on pumping, } \\
\text { heads, flows }\end{array}$ & $\begin{array}{l}\text { Optimal boundary flows } \\
\text { Optimal heads at "variable" head cells } \\
\text { Optimal pumping }\end{array}$ \\
\hline
\end{tabular}


An S/O model can be used to lirectly calculate an optimal pumping strategy for the goal of minimizing the pumping needed to capture the plume without causing unacceptable consequences. For example, assume that no injection mounds should reach the ground surface and that no drawdowns should exceed $2 \mathrm{~m}$. In addition, assume that potentiometric surface gradients near the plume should be toward the plume source.

The S/O model will directly calculate the minimum total pumping rate needed and will identify how much should be.pumped from each pumping location. The potentiometric surface heads and gradients that will result from the optimal pumping will lie within the bounds specified initially (Table 1). In other words, future heads will not reach the ground surface, future heads will not be more than $2 \mathrm{~m}$ below current heads, and final gradients will be toward the contaminant source. Thus, the very first optimal pumping strategy computed by an S/O model will satisfy all specified management goals.

\section{COMMON S/O MODELING APPROACHES AND LIMITATIONS}

Most S/O models employ either an embedding or a response matrix approach for representing system (head) response to pumping [5]. Embedding models contain finite-difference or finiteelement equations embedded directly as constraints. In a finite-difference embedding model, head and pumping values (or other flows) must be computed for each time step at each cell. This is a very useful approach for those situations in which (1) pumping should be a decision variable at most cells, (2) head must be constrained in a high proportion of cells, and (3) either a steady-state strategy should be developed or there need be very few time steps. It is not as desirable if there are relatively few pumping cells and control points or if many time steps are needed. Thus, embedding models have been mainly used for steady-state regional planning and for small hypothetical problems.

Response matrix S/O models use linear systems theory and superposition with influence coefficients (e.g., [6]-[14] and many others). The matrix containing the influence coefficients and superposition (summation equations) is termed the response matrix. Response matrix (RM) models use a two-step process. First, normal simulation (analytical or numerical) is used to calculate system response to assumed unit stimuli. Then optimization is performed by an S/O model that includes summation equations (discretized forms of the convolution integral).

Response matrix models are ideal for transient management situations. They require constraint equations for only those specific cells and time steps at which head or flow (other than pumping) must be restricted during the optimization. To predict system response to the optimal strategy at locations and times other than those constrained in the S/O model, an external simulation model is used after the optimization.

Regardless of the simulation approach used, S/O models share some of the limitations of standard simulation models. Poor physical system representation or inadequate data will cause error. One cannot properly optimize management of system processes that one cannot correctly simulate. Useful simulation/optimization modeling presupposes that aquifer parameters are appropriate and that actual boundary conditions are represented adequately within the model.

Both embedding and RM S/O models generally assume system linearity during at least some part of their processing operation. Confined aquifers are linear, unless they become unconfined. Unconfined aquifers are nonlinear, but frequently the change in transmissivity is insignificant, and they can be treated as if they were linear. Most commonly, system nonlinearity is addressed by cycling. Cycling involves (1) assuming aquifer parameters (and computing influence coefficients for RM models), (2) calculating an optimal strategy, (3) recalculating system parameters, (4) comparing assumed and newly calculated parameter values, and (5) either stopping or returning to step 2 and repeating the process (if the assumed parameter values are 
still inappropriate for the problem or if the optimal strategy is still changing with cycling). Frequently, three cycles are sufficient for this convergence process. Thus, although both types of models are completely applicable for confined aquifers, some adjustments must be made to àccurately apply them to unconfined aquifers.

Within S/O models, plume capture is generally achieved by controlling hydraulic gradients and thus controlling advective transport. Generally, nonlinear transport equations are not included. This approach permits the modeler to retain use of the characteristics of linear systems (superposition, etc.). All of the RM model applications presented below achieve capture via gradient control.

Concerning data input, S/O models require all of the data needed by simulation models, plus information on lower and upper bounds on decision variables (pumping rate, location) and state variables (head, gradient, etc.). Although the same sort of information should be required when using an S model, the forced codification of these data as S/O model input is helpful. It causes the modeler to specify strategy acceptability criteria earlier than he/she might otherwise.

Concerning model results, an S/O model might tell a user that the posed problem is infeasible. This means that the user has posed a problem for which all the constraints cannot be satisfied simultaneously. For example, the user might have instructed the model to cause the head near an injection cell to reach at least $100 \mathrm{~m}$ above mean sea level and simultaneously told it that the upper bound on injection in $50 \mathrm{~m}^{3} / \mathrm{day}$. If that injection rate is inadequate to cause the required change in head, the model will declare the problem to be infeasible. The model will be unable to determine even one pumping rate that can satisfy both conditions.

Of course, if there is more than one potential injection well, the same problem might be feasible. In that case, the model can compute an optimal pumping strategy (probably the user would have requested a strategy that minimizes the total pumping needed to achieve that head).

Fortunately, S/O model users rapidly get beyond the stage wherein they try to develop impossible pumping strategies (force the model to achieve goals that are impossible or mutually exclusive when considering both the laws of nature and the goals of humans). Experience brings the S/O modeler great ability to address common management problems.

\section{PC-BASED S/O MODELS AND SAMPLE APPLICATIONS}

\section{A. US/WELLS ${ }^{D}$ for Systems Addressable Using Analytical Solutions}

1. Model Background

US/WELLS ${ }^{\mathrm{D}}$ (Utah State extraction/injection well system for optimal groundwater management) is a deterministic version of an RM model. It uses influence coefficients based on analytical equations for potentiometric surface response to pumping and river depletion resulting from pumping. It is appropriate for systems where those analytical approaches are appropriate-presumably relatively homogeneous systems. (Of course, in the management and consulting arena, such approaches are commonly applied to heterogeneous systems, with acceptable error.)

Characteristics of US/WELLS ${ }^{D}$ are summarized in Table 2. The overview below is derived from the user's manual [15].

The objective function of the optimization module in US/WELLS is generally applicable and easily used for a variety of situations. The user can select either a linear or a quadratic form. The linear objective function is to minimize

$$
\sum_{x=1}^{2}\left[W_{E, x} \sum_{j=1}^{J} E_{j, x}+W_{I, x} \sum_{k=1}^{K} I_{k, x}\right]
$$


Table 2 Characteristics of US/WELLS ${ }^{\mathrm{D}}$ and US/REMAX ${ }^{\mathrm{B}}$

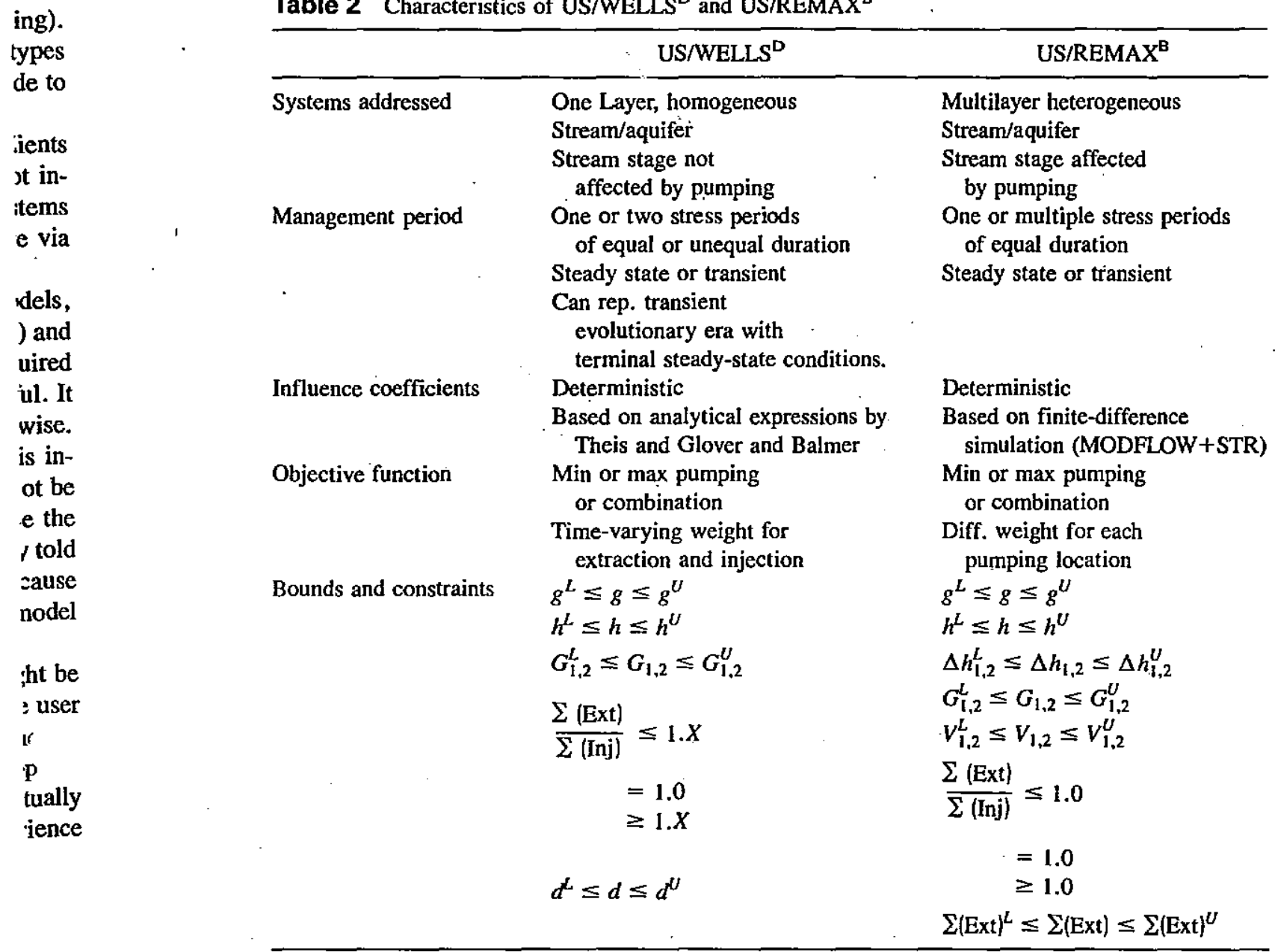

Notes: Superscripts $L$ and $U$ refer to lower and upper bounds; $g=$ extraction or injection, [ $\left.\mathrm{L}^{3} / \mathrm{T}\right] ; h=$ head.; $\Delta h$, $G_{t, 2}, V_{1,2}=$ head-difference, gradient, and velocity, respectively, between any two locations, [L], dimensionless,

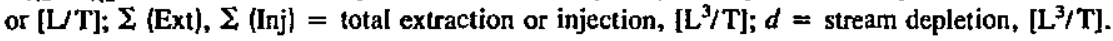

magem anulting ropri-

I conwith

arived

icable dratic where $W_{E, x}$ and $W_{I, x}$ are the cost coefficient or weight assigned to extraction $(E)$ or injection (I) rates in the $x_{\text {th }}$ time period, [ $\$ /\left(\mathrm{L}^{3} \cdot \mathrm{T}\right)$ ] or dimensionless; $E_{j, x}$ and $J_{k, x}$ are extraction $(E)$ or injection $(I)$ rate at well $j$ (or $k$ ) in the $x_{\text {th }}$ time period, $\left[\mathrm{L}^{3} / \mathrm{T}\right]$; and $J$ and $K$ are number of extraction $(J)$ or injection $(K)$ wells.

Potential constraints are the following.

1. Hydraulic gradient between any gradient control pair of wells at any time period must be within user-speciffed bounds. This can ensure that water is moving only in the desired direction. The maximum value can differ for each gradient control pair and time period. This constraint is useful, for example, when US/WELLS ${ }^{D}$ is used for groundwater contaminant plume immobilization or for any situation where hydraulic gradient control is desired.

2. Extraction or injection rate at any well must be withiri user-specified bounds (lower and upper limits). If the user cannot decide if a certain well should be used fol-extraction or injection, he can locate one of each at the same location. The model will then determine either an extraction or an injection rate, or neither, for that location. 
3. Hydraulic head at any injection, extraction, or observation well must be within userspecified lower and upper bounds. For example, a lower bound may be used to maintain adequate saturated thickness. An upper bound may be used to prevent surface flooding or to eliminate the need for pressurized injection. These lower and upper bounds can differ for different locations. The bounds are the same for both time periods.

4. Total import or export of water can be controlled to be within a user-specified range. The user can also completely prevent import or export of water or both. If no import or export of water is allowed, the total optimal extraction must equal the total optimal injection.

5. Depletion from the river must be within user-specified bounds (lower and upper limits). 7his is applicable only if a river exists in the considered system.

6. Constraint 3 is modified such that the probability that the actual change in head at any point in the groundwater system is not less than the change calculated by the model or is not greater than the change calculated by the model and is at least equal to the reliability level specified by the user. (This ability is found only in an alpha-test chance-constrained version of the model, US/WELLS ${ }^{\mathbf{S}}$, which considers the stochastic nature of hydraulic conductivity. The utilized chance constraint is more accurate than previously reported formulations.)

Optionally, US/WELLS ${ }^{\mathrm{D}}$ can use a quadratic objective function to minimize

$$
\sum_{x=1}^{2}\left[W W_{E, x} \sum_{j=1}^{J} E_{j, x} H_{j, x}+W_{E, x} \sum_{j=1}^{J} E_{j, x}+W_{l, x} \sum_{k=1}^{K} I_{k, x}\right]
$$

where $H_{j, x}$ is the dynamic lift, the difference between ground surface elevation and optimal potentiometric head resulting at extraction well $j$ at the end of the $x_{\text {th }}$ time period, [L]; and $W W_{E, x}$ is the weight assigned to the power used for extraction in the $x_{\mathrm{th}}$ time period, [\$/L-T)].

The weighting factors can be used to emphasize different criteria and different time periods. For example, assume a problem of minimizing the total extraction using the linear objective function. If the second time period is chosen to be much longer than the first time period and the weights assigned to extraction and injection in the second time period are larger than those used for the first time period, then the solution will tend to minimize steady-state extraction/injection rates, and less attention will be given to the short-term transient rates. Through the weighting factors, US/WELLS ${ }^{\mathrm{D}}$ can also be used for maximizing pumping rates for water supply problems.

\section{Application and Results}

Here we illustrate the use of US/WELLS ${ }^{D}$ to determine the optimal time-varying sequence of extraction and injection of water in prespecified locations needed for first immobilizing and then extracting a groundwater contaminant plume. In this example, the user specifies potential locations of extraction and injection wells around the contaminant plume (Figure 1). US/ WELLS $^{\mathrm{D}}$ then determines optimal extraction and injection rates for different time periods.

To illustrate model flexibility, four potential extraction wells and five potential injection wells are considered for placement outside the contaminant plume during the first period. In the second time period, three extraction wells are considered for placement inside the plume (to extract contaminated water) and five potential downgradient injection wells are considered. During both periods, the resulting hydraulic gradients (between 10 pairs of head observation locations) must be toward the center of the plume. Alternatively, the user could choose to minimize the pumping needed to capture the plume using only internal extraction wells in one or both periods. 
ser-

tain

; or

for

The

sort

l.

ts).

any

$r$ is

lity

ned

lic

ted

mal

$\vdots$

Г) 1 .

ari-

iec-

iod

han

ex-

tes.

Ites

$\geqslant$ of

and

tial

US/

i.

ion

the

(to

ed.

ion

in-

; or

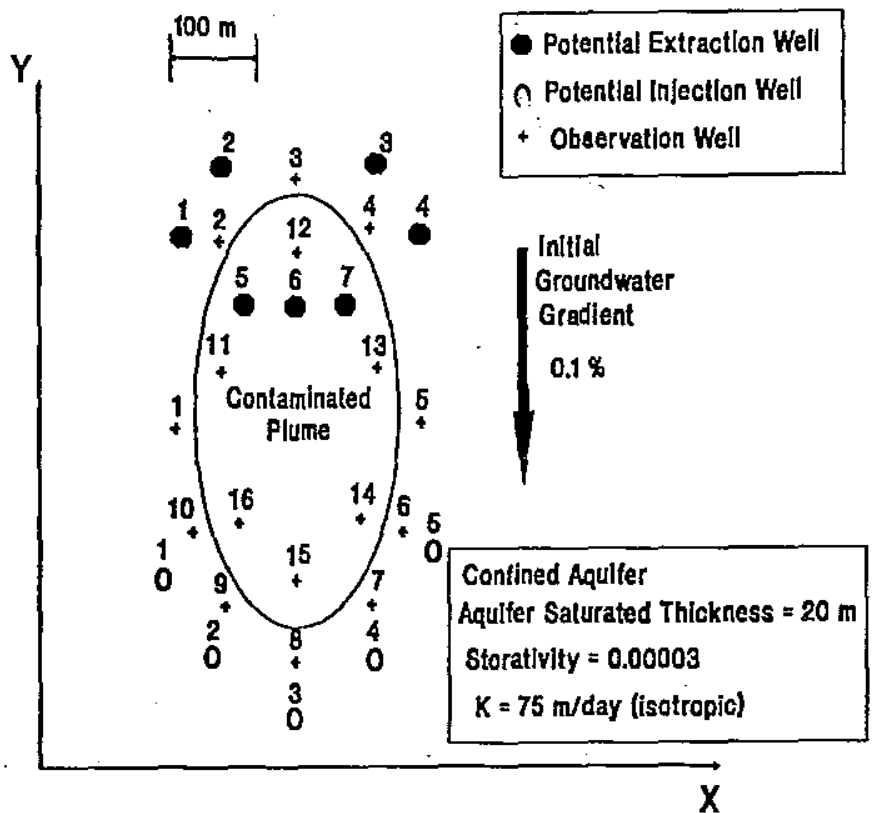

Figure 1 Hypothetical study area for Example A, addressable with US/WELLS ${ }^{\mathrm{D}}$.

Here, the quadratic objective function is used and employs greater weights for the second time period than the first period. This supports the fact that the second period is much longer than the first. In addition, neither export nor import of water is allowed-total injection must equal total extraction in each period. All the above considerations are incorporated within the model via the input data [15]. The user also specifies lower and upper bounds on head and pumping rates.

Figure 2 shows US/WELLS ${ }^{\mathrm{D}}$ output, in meters and $\mathrm{m}^{3} / \mathrm{day}$. This contains, in addition to the input bounds (L. Bound and U. Bound), the optimal values of the decision variables (pumping), state variables (head and gradient), and marginal values.

The marginal is defined as the value by which the objective function will change if a tightly bounded variable changes one unit. If a variable's optimal value is not equal to either its lower or upper bound, its marginal will be zero. That is, the marginal will be nonzero only if the optimal value of the variable equals one of its bounds. In this case, the marginal shows the improvement of the value of the objective function resulting from relaxing this bound by one unit. Marginals are valid only as long as no other variable also changes in value. Thus they might be valid for only a small range of change in the bound.

To illustrate, the output file (Figure 2) shows that the marginal of the optimal injection rate in the first time period at injection well 3 is -45.3 . The objective function value was $334,668.1$. If the upper bound on injection in the first time period is relaxed by one unit at the mentioned well (that is, the new upper bound is 901 instead of 900 ), one would expect the value of the objective function to change by about -45.3 to $334,622.8$. If this change is actually made and the model is rerun, the resulting change in objective function value is -45.4 .

Marginals are useful in determining how to refine an optimal strategy. They help one to decide which bounds or constraints should be looked at more closely and perhaps relaxed. They also indicate the trade-off between that bound and objective achievement. They show how much one is giving up in terms of objective attainment to satisfy that restriction. 
MODEL STATUS : OPTIMAL SOLUTION FOUNO VALUE OF OBJECTIVE FUNCTION 334668.1

\section{OPTIMAL EXTRACTION RATES}

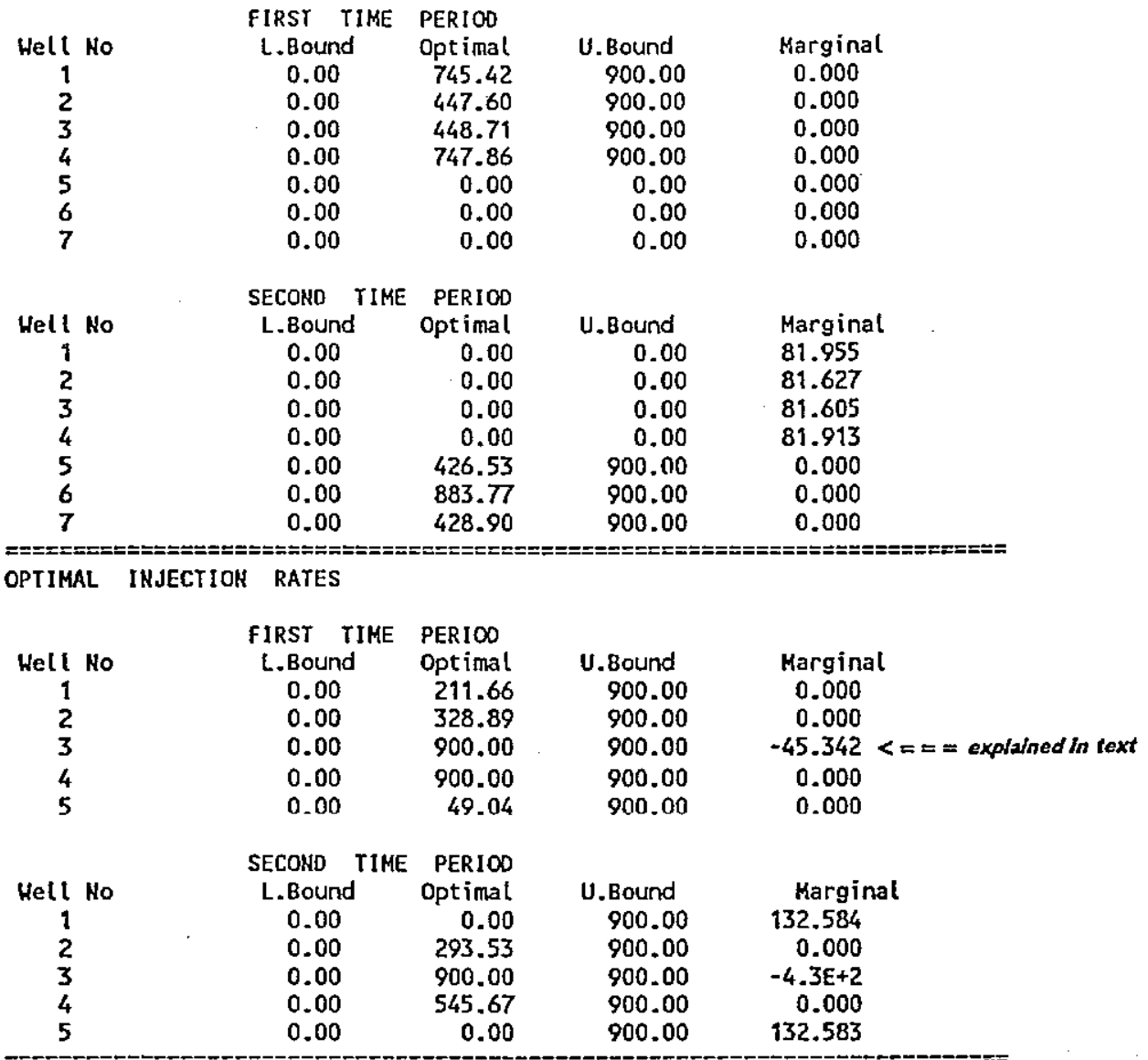

OPTIMAL HEADS AT OBSERVATION HELLS

\begin{tabular}{|c|c|c|c|c|}
\hline & FIRST TIKE & PERIOD & & \\
\hline Hell No & L.Bound & Optimal & U.Bound & Harginal \\
\hline $\begin{array}{l}1 \\
2\end{array}$ & $\begin{array}{l}30.00 \\
30.00\end{array}$ & $\begin{array}{l}35.69 \\
35.54\end{array}$ & $\begin{array}{l}40.00 \\
40.00\end{array}$ & $\begin{array}{l}0.000 \\
0.000\end{array}$ \\
\hline 3 & 30.00 & $\begin{array}{l}33.34 \\
35.60\end{array}$ & $\begin{array}{l}40.00 \\
40.00\end{array}$ & 0.000 \\
\hline 4 & 30.00 & 35.55 & 40.00 & 0.000 \\
\hline 5 & 30.00 & 35.70 & 40.00 & 0.000 \\
\hline 6 & 30.00 & 35.79 & 40.00 & 0.000 \\
\hline 7 & 30.00 & 35.92 & 40.00 & 0.000 \\
\hline 8 & 30.00 & 35.88 & 40.00 & 0.000 \\
\hline 9 & 30.00 & 35.84 & 40.00 & 0.000 \\
\hline 10 & 30.00 & 35.77 & 40.00 & 0.000 \\
\hline 11 & 30.00 & 35.65 & 40.00 & 0.000 \\
\hline 12 & 30.00 & 35.60 & 40.00 & 0.000 \\
\hline 13 & 30.00 & 35.65 & 40.00 & 0.000 \\
\hline 14 & 30.00 & 35.79 & 40.00 & 0.000 \\
\hline 15 & 30.00 & 35.88 & 40.00 & 0.000 \\
\hline 16 & 30.00 & 35.77 & 40.00 & 0.000 \\
\hline
\end{tabular}

Figure 2 US/WELLS ${ }^{\mathrm{D}}$ output file for Example A. 
SECONO TIME PERIOD

$\begin{array}{ccccc}\text { Hell No } & \text { L.Bound } & \text { Optimal } & \text { U.Bound } & \text { Marginal } \\ 1 & 30.00 & 35.62 & 40.00 & 0.000 \\ 2 & 30.00 & 35.62 & 40.00 & 0.000 \\ 3 & 30.00 & 35.68 & 40.00 & 0.000 \\ 4 & 30.00 & 35.62 & 40.00 & 0.000 \\ 5 & 30.00 & 35.63 & 40.00 & 0.000 \\ 6 & 30.00 & 35.66 & 40.00 & 0.000 \\ 7 & 30.00 & 35.75 & 40.00 & 0.000 \\ 8 & 30.00 & 35.74 & 40.00 & 0.000 \\ 9 & 30.00 & 35.71 & 40.00 & 0.000 \\ 10 & 30.00 & 35.64 & 40.00 & 0.000 \\ 11 & 30.00 & 35.56 & 40.00 & 0.000 \\ 12 & 30.00 & 35.54 & 40.00 & 0.000 \\ 13 & 30.00 & 35.56 & 40.00 & 0.000 \\ 14 & 30.00 & 35.66 & 40.00 & 0.000 \\ 15 & 30.00 & 35.74 & 40.00 & 0.000 \\ 16 & 30.00 & 35.64 & 40.00 & 0.000\end{array}$

OPTIMAL HEADS AT EXTRACTION WELLS

FIRST TIME PERIOD

$\begin{array}{cccll}\text { Hell No } & \text { L.Bound } & \text { Optimal } & \text { U.Bound } & \text { Harginal } \\ 1 & 30.00 & 35.09 & 40.00 & 0.000 \\ 2 & 30.00 & 35.29 & 40.00 & 0.000 \\ 3 & 30.00 & 35.29 & 40.00 & 0.000 \\ 4 & 30.00 & 35.09 & 40.00 & 0.000 \\ 5 & 30.00 & 35.61 & 40.00 & 0.000 \\ 6 & 30.00 & 35.62 & 40.00 & 0.000 \\ 7 & 30.00 & 35.61 & 40.00 & 0.000 \\ & & & & \\ & \text { SECOND TIME } & \text { PERIOD } & & \\ \text { Well No } & & & & \\ 1 & \text { L.BOund } & \text { Optimal } & \text { U.Bound } & \text { Marginal } \\ 2 & 30.00 & 35.69 & 40.00 & 0.000 \\ 3 & 30.00 & 35.72 & 40.00 & 0.000 \\ 4 & 30.00 & 35.73 & 40.00 & 0.000 \\ 5 & 30.00 & 35.70 & 40.00 & 0.000 \\ 6 & 30.00 & 35.24 . & 40.00 & 0.000 \\ 7 & 30.00 & 34.90 & 40.00 & 0.000 \\ & 30.00 & 35.25 & 40.00 & 0.000\end{array}$

HEAOS OPTIMAL HEADS AT INJECTION WELLS

\section{FIRST TIME PERIOO}

$\begin{array}{cclll}\text { Hell No } & \text { L.8ound } & \text { Optimal } & \text { U.Bound } & \text { Marginal } \\ 1 & 30.00 & 35.90 & 40.00 & 0.000 \\ 2 & 30.00 & 36.03 & 40.00 & 0.000 \\ 3 & 30.00 & 36.46 & 40.00 & 0.000 \\ 4 & 30.00 & 36.47 & 40.00 & 0.000 \\ 5 & 30.00 & 35.83 & 40.00 & 0.000 \\ & & & & \\ & \text { SECOND TIME } & \text { PERIOD } & & \\ \text { Hell Ho } & & & & \text { M.Bound } \\ 1 & \text { L.Bound } & \text { Optimal } & \text { Marginal } \\ 2 & 30.00 & 35.65 & 40.00 & 0.000 \\ 3 & 30.00 & 35.88 & 40.00 & 0.000 \\ 4 & 30.00 & 36.33 & 40.00 & 0.000 \\ 5 & 30.00 & 36.08 & 40.00 & 0.000 \\ & 30.00 & 35.67 & 40.00 & 0.000\end{array}$


OFTIMAL HYDRAULIC GRAOIENTS

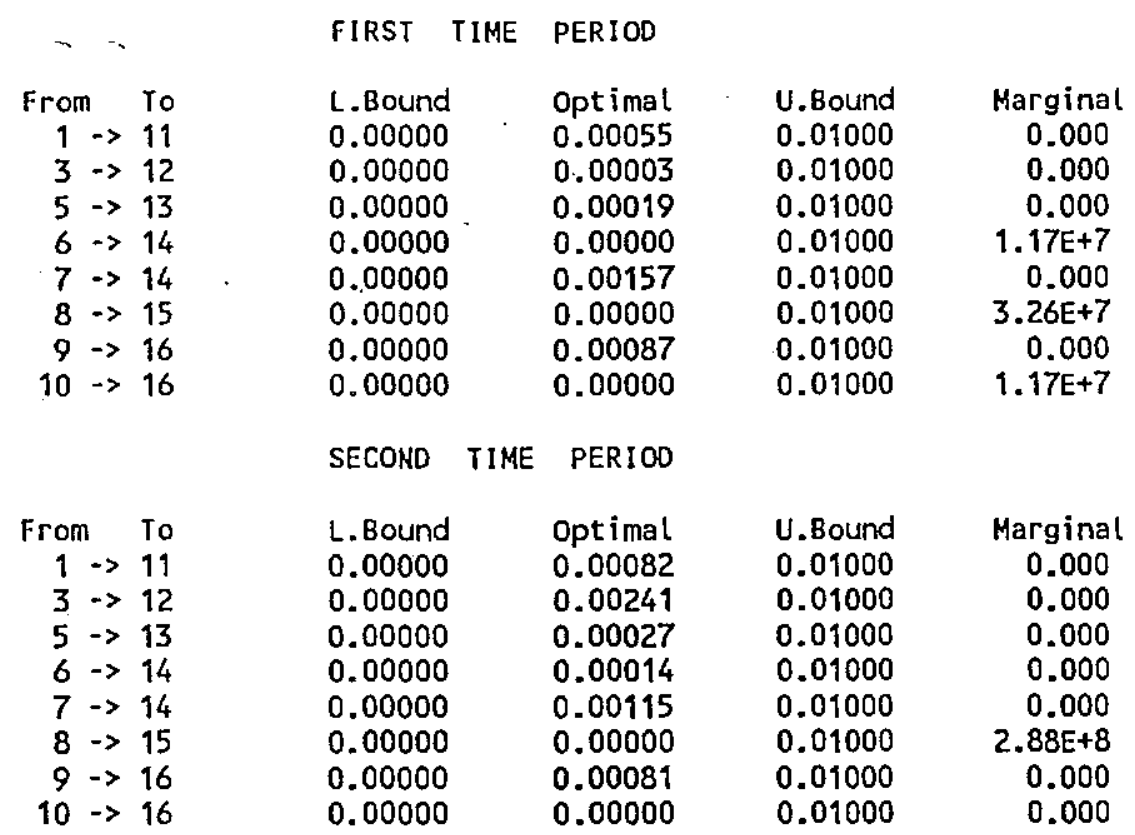

Figure 2 Continued.

\section{B. US/REMAX ${ }^{\text {B }}$ for Heterogeneous Multilayer Systems}

1. Model Background

For optimizing management of complex heterogeneous systems, one would rather use US/ REMAX $^{\mathrm{B}}$ [16] than US/WELLS ${ }^{\mathrm{D}}$. This is the basic version of the Utah State response matrix model. To develop influence coefficients, it uses code modified from MODFLOW, a modular finite-difference groundwater flow simulation model [4], and STR; a related stream routing module [17]. The physical system data needed by US/REMAX ${ }^{\mathrm{D}}$ can be input in the same format as is used by MODFLOW and STR. Internally, US/REMAX ${ }^{\mathrm{B}}$ also uses a portion of PLUMAN, a decision support system for optimal groundwater contaminant plume management [18], and other code.

The optimization model formulation capabilities are similar to those of US/WELLS ${ }^{\mathrm{D}}$ (Table 2). For steady state, the generic objective is to minimize

$$
\sum_{j=1}^{J} W_{j} E_{j}+\sum_{k=1}^{K} W_{k} I_{k}
$$

where $W_{j}$ is the weight assigned to pumping in cell $j$, dimensionless or $\left[\$ \cdot T / L^{3}\right]$.US/REMAX ${ }^{B}$ can employ constraints 1-3 of US/WELLS ${ }^{\mathrm{D}}$ for multiple layers. Similar to the US/WELLS constraint 4, US/REMAX ${ }^{B}$ can force total extraction to exceed, equal, or be less than total injection. Again, via the sign on the weighting coefficients, one can perform maximization. One can also achieve multiobjective optimizization by the weighting method. Whereas in US/ WELLS $^{\mathrm{D}}$ the same weight must be applied to all extraction wells in a time step (and a different weight can be used for injection wells, but the same must be applied to all such wells in a particular time step), in US/REMAX ${ }^{B}$ each well can employ a different weight. 
2. Application and Results

Introduction. For illustration, we discuss addressing a contaminant plume in a representative study area. First, the study area is described and the results of continuing current management are predicted, using MODFLOW+STR for flow simulation and MOC [19] for transport simulation. Then an approach to developing an optimal strategy is discussed, the $S / O$ model is applied, and an optimal strategy is computed. Next, the system response to implementing the optimal strategy is verified using MODFLOW+STR and MOC. Finally, slight variations in the management goal or situation are assumed and new optimal strategies are developed. Computed optimal strategies are compared. Suguino [20] first addressed this study area using PLUMAN. Some of the discussion below follows his development.

Study Area Description and Situation. The area (Figure 3) measures about $4.3 \mathrm{~km}$ by $4.3 \mathrm{~km}$. It is bounded on the north by a large saltwater body; on the south, east, and northwest by impermeable material; and on the west by a lake. A river transects the area from south to north. Aquifer parameters of this example study area were obtained from ranges reported by Todd [21]

For the unconfined upper layer (layer 1), parameters are as follows.

Hydraulic conductivity:

1st zone: $45 \mathrm{~m} /$ day (coarse sand) from lake to contaminant spill area (columns $1-36$ and 57-58)

2nd zone: $30 \mathrm{~m} /$ day (medium sand) in irrigated area (columns 51-56)

3rd zone: $450 \mathrm{~m} /$ day (fine gravel) in contaminant spill area (columns $37-50$ ).

Specific yield:

1st zone: 0.27 (coarse sand)

2nd zone: 0.28 (medium sand)

3rd zone: $\mathbf{0 . 2 5}$ (fine gravel)

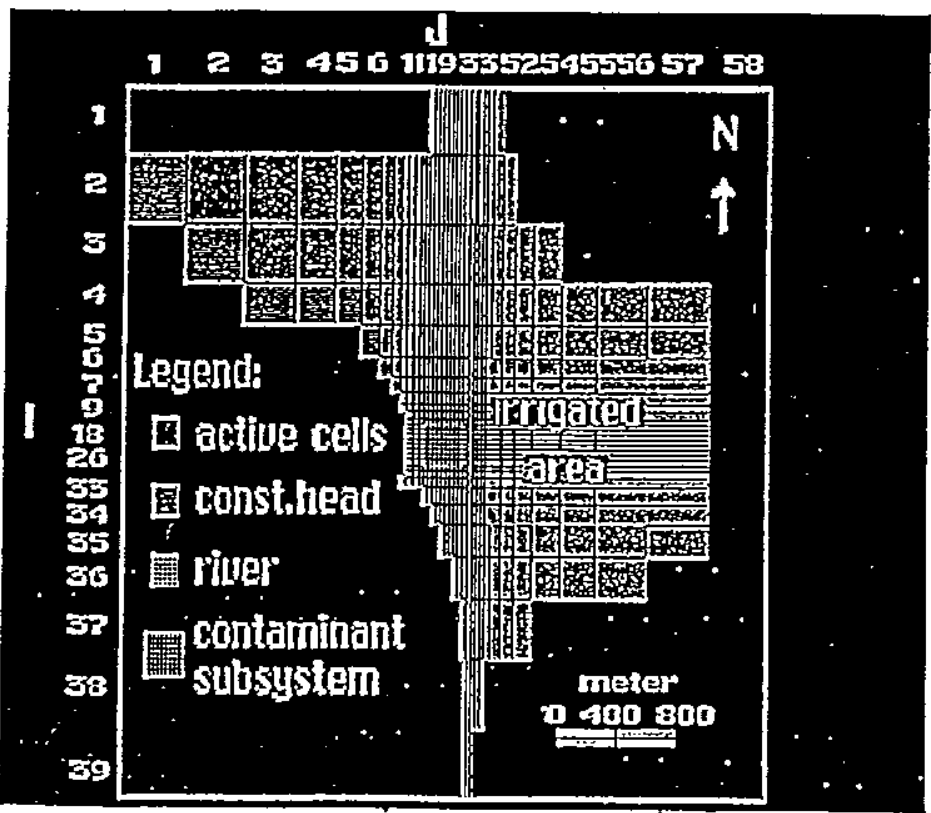

Figure 3 Finite-difference grid for the area addressable with US/REMAX ${ }^{\mathbf{B}}$. 
Recharge by deep percolation and/or irrigation:

$1.167 \times 10^{-8} \mathrm{~m} / \mathrm{sec}$ in nonirrigated area

$1.928 \times 10^{-18} \mathrm{~m} / \mathrm{sec}$ in irrigated area

In the confined lower layer (layer 2):

Transmissivity: $\quad 0.1564 \mathrm{~m}^{2} / \mathrm{sec}$

Saturated thickness: $30.0 \mathrm{~m}$

Storage coefficient: $\quad 0.0001$

Finite-difference models are to be used in this study. This requires system discretization. The resulting block-centered cell grid (Figure 3 ) has 58 columns and 39 rows. Cell side lengths range from 3 to $400 \mathrm{~m}$. Because MOC will be used for transport simulation near the plume, cells of uniform size are specified for that region. The resulting 17 row by 20 column region (subsystem) near the plume has square cells of $15.2 \mathrm{~m}$ (50 ft) side length.

A conservative (nonreactive) contaminant is assumed to be spilled in the top aquifer layer (layer 1 ) of cell $(22,18)$ or $\left(11_{s}, 3\right)$. (The subscript " $s$ " after a cell row or column index indicates that the cell is in the subsystem.) This cell is treated as a continuous source during the management period.

Initially, pumping for water supply occurs in two cells between the plume and the river. One well is in layer 1 of $(23,15)$ or $\left(12,15_{s}\right)$. The other well is in layer 2 of $(18,18)$ or $(7 s$, $18_{\mathrm{s}}$ ). There is immediate concern about the potential for contamination reaching the supply well in layer 1 .

Nonoptimal System Response Determination (Step l). Before one attempts to develop an optimal strategy, one usually demonstrates the need for such a strategy. This requires predicting system response if no optimal strategy is implemented. Frequently, simulation models are used for this action. Here, MODFLOW + STR computes the potentiometric surface that will result from assumed steady-state conditions (Figure 4).

Because of the gradient, the contaminant will tend to migrate toward the supply wells. MOC is used to quantify the migration resulting in the subsystem from the steady flow. Figure 5 shows the $210 \mathrm{ppb}$ contour expected to result 60 days after contamination begins. Furthermore, concentration in the cell containing the drinking well $\left(12_{\mathrm{s}}, 15_{\mathrm{s}}\right)$ reaches $317 \mathrm{ppb} 8$ months after the spill. We assume that this concentration level exceeds the health advisory for human consumption and that developing a plume capture strategy is desirable.

Management Goals Specification and S/O Model Formulation for Scenario I (Step 2). The assumed goal is to minimize the steady pumping (extraction and injection) needed to capture the plume. Plume capture will presumably be achieved when hydraulic gradients, just outside the plume boundary, all point toward the plume interior. We also want the head at extraction wells not to drop too far (to avoid reducing saturated thickness by more than about $10 \%$ ) or the head at injection wells not to rise to the ground surface. These criteria identify the example problem termed Scenario 1.

The S/O model formulation for this scenario is shown below. The model computes the pumping strategy that minimizes the value of the objective function, subject to the stated constraints and bounds. Locations of potential injection and extraction wells to be considered by the model are shown in Figure. 5. Figure 6 identifies head difference (gradient) control cell pairs and shows the direction that will be imposed ofi the hydraulic gradient by any computed optimal strategy. These are placed to enclose the plume projected to exist by day 60 . A modeler can select potential well locations on the basis of practical experience. For example, the closer the injection wells are to the head gradient control locations, the less pumping is needed to 
tion.

igths

ume,

'gion

layer

$x$ in-

g the

:iver.

$:\left(7_{\mathrm{s}}\right.$,

ipply

1

$2 t_{1 t_{20}}$ used esult

rells.

gure

ther-

inths

man

The

ture

tside

tion

$r$ the

nple

, the

con-

d by

cell

uted

leler

oser

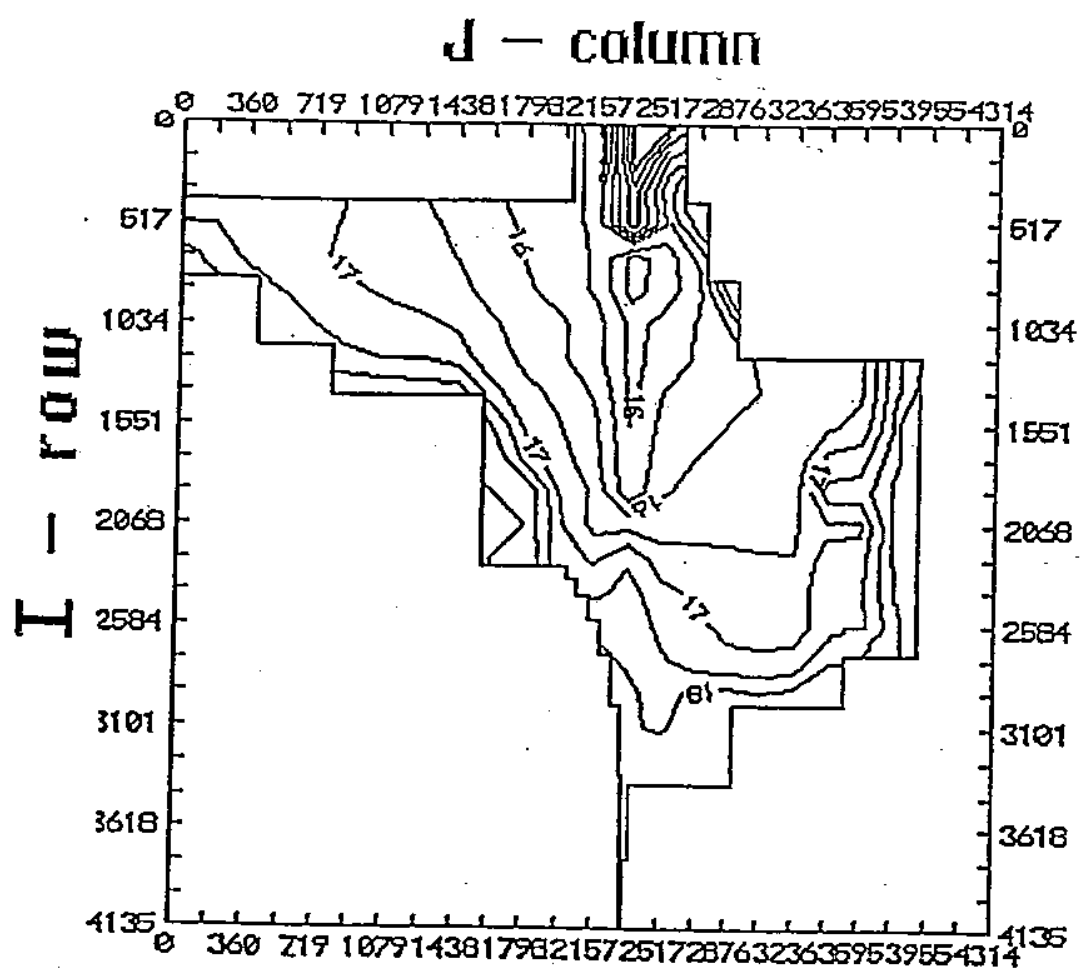
Figure 4 Nonoptimal (unmanaged) steady-state potentiometric surface contour map for the study area
of Scenario 1 (meters above MSL).

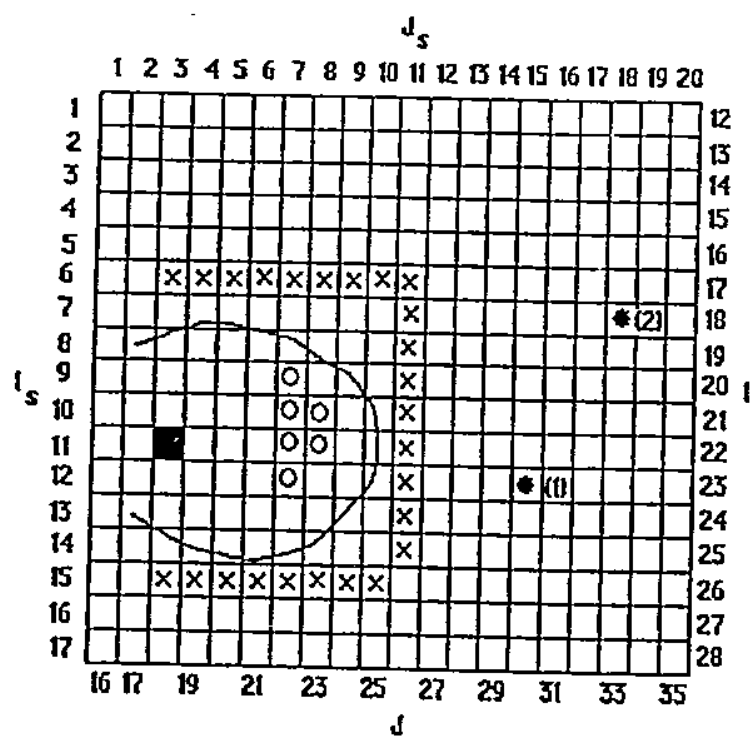

Legend:

6 unmanaged well

(I) layer 1

(2) layer 2

Dotential managed

injection well

[2] potential managed

estraction well

contaminant source

$210 \mathrm{ppb}$ concentration

confour

0 meter

153045

Figure 5 Subsystem discretization, potential well locations for Scenario 1, and 210 ppm contour, 60 d' 


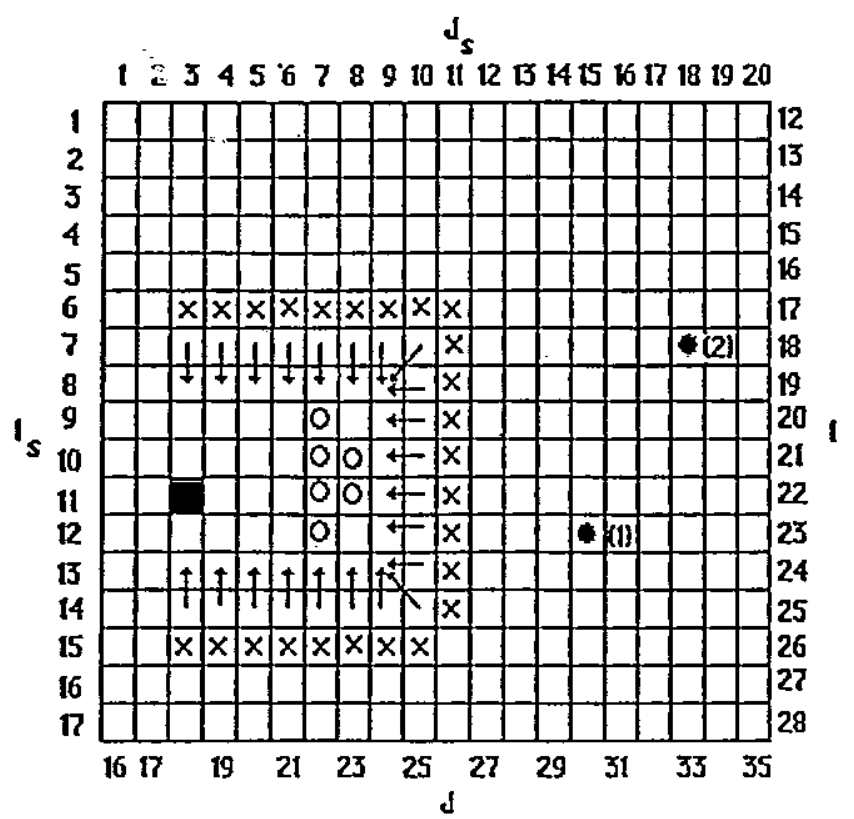

Legend:

(1) unmanaged well

(1) layer 1

(2) layer 2

(x) potential managed

injection well

(upper bound on head)

[. potential managed

estraction well

Dower bound on headl

- contaminant source

$\leftarrow$ gradient constraint

$0153045 \mathrm{~m}$

Figure 6 Head-difference constraint locations applied within the S/O model in Scenario 1.

satisfy the head-difference constraint. Thus, the modeler might want the model to consider pumping sites near the location where heads need most to be affected.

The model objective is to minimize the value of Equation (3), using weights of 1 , subject to

$$
\begin{array}{ll}
G_{\bar{o}} \geq 0.01, & \text { for } \bar{o}=1, \ldots, 22 \\
h_{\hat{e}} \geq 15.0, & \text { for } \hat{e}=1, \ldots, 6 \\
h_{\hat{e}} \leq 25.0, & \text { for } \hat{e}=1, \ldots, 25
\end{array}
$$

where $G_{\bar{o}}$ is the difference in head between a pair of cells, the first located farther from the plume. A positive value denotes a higher head farther from the plume, [L]; $h_{\vec{e}}$ is the hydraulic head just outside the casing of pumping well $\hat{e}$ located in the center of a pumping cell, [L]; $\vec{o}$ is the index denoting pair of cells head-difference (gradient) control pair; and $\hat{e}$ is the index denoting pumping well at the center of cell $j$ or $k$. Here $j=6$ and $k=25$.

Note that identifying the location of potential extraction and injection wells for the model (Figure 5) does not mean that the model will choose to pump at those locations. Via the optimization process, the model might choose to pump at only a few of the potential sites. The computed strategy will require less total pumping than any other strategy possible for the specified potential well locations and imposed bounds and constraints. Furthermore, since this is a steady-state problem, steady-state system response to implementing the strategy computed by the model will satisfy all those bounds and constraints. This is verified in the next step.

Optimal Strategy Computation and Verification for Scenario 1 (Step 3). The optimal strategy computed for Scenario 1 is shown in Table 3 . Because the model is minimizing pumping only for plume containment in layer 1 , no extraction is shown for layer 2 . The original unmanaged pumping does continue from original supply wells in both layers (Figure 3 ) but is not included in Table 3 because the model is not optimizing that pumping. 
Table 3 Pumping Results for the Sample Scenarios

\begin{tabular}{|c|c|c|c|c|c|}
\hline \multirow[b]{2}{*}{ Scenario } & \multirow[b]{2}{*}{ Constraints } & \multicolumn{2}{|c|}{$g(\mathrm{e} \times \mathrm{tr})$} & \multirow{2}{*}{$\begin{array}{c}b \text { (inj.) } \\
\left(\mathrm{m}^{3} / \mathrm{sec}\right)\end{array}$} & \multirow{2}{*}{$\begin{array}{l}(g+b) \text { total } \\
\quad(\mathrm{gpm})\end{array}$} \\
\hline & & 1st Layer & 2nd Layer & & \\
\hline 1 & $\begin{array}{l}\text { Gradient constraint on } \\
\text { heads.located on the same } \\
\text { layer, head constraint on } \\
\text { injection and extraction well. }\end{array}$ & $\begin{array}{r}0.01338 \\
(212.05)\end{array}$ & - & $\begin{array}{l}0.02020 \\
(320.13)\end{array}$ & $\begin{array}{l}0.03358 \\
(532.18)\end{array}$ \\
\hline 2 & $\begin{array}{l}\text { Added pumping constraint: } \\
\text { total sum of extraction }=\text { total } \\
\text { sum of injection. }\end{array}$ & $\begin{array}{r}0.01702 \\
(269.74)\end{array}$ & - & $\begin{array}{l}0.01702 \\
(269.74)\end{array}$ & $\begin{array}{l}0.03404 \\
(539.48)\end{array}$ \\
\hline 3 & $\begin{array}{l}\text { Gradient constraint on heads } \\
\text { located on the same and on } \\
\text { different layers, head constraint } \\
\text { on injection and extraction wells. }\end{array}$ & $\begin{array}{l}0.00300 \\
(47.54)\end{array}$ & $\begin{array}{l}0.00329 \\
(52.14)\end{array}$ & $\begin{array}{l}0.03786 \\
(600.03)\end{array}$ & $\begin{array}{l}0.04415 \\
(699.69)\end{array}$ \\
\hline
\end{tabular}

Figure 7 shows the locations of wells that will pump, according to the optimal strategy. It also shows the head-difference constraints [Equation (4)] that will be tight. Tight constraints are those that are satisfied exactly. The other gradient constraints are also satisfied, but the model had no difficulty in doing so. These latter head-difference constraints are "loose" (there is more than $0.01 \mathrm{~m}$ difference between the heads at the two cells coupled by an arrow in Figure 6 but not shown at all in Figure 7). No heads are against their bounds. Therefore neither Equation (5) nor (6) is tight.

It is appropriate to verify that the computed strategy accomplished its goal of plume capture. MODFLOW+STR can be used to demonstrate how quickly the optimal steady pumping

(4)

(5)

(6)

the

lic

1; $\bar{o}$

$\operatorname{lex}$

del

op-

The

ec-

is a

by

'gy

nly

yed

led $\mathbf{d}_{s}$

123456789 10 11 121314151617 18 1920

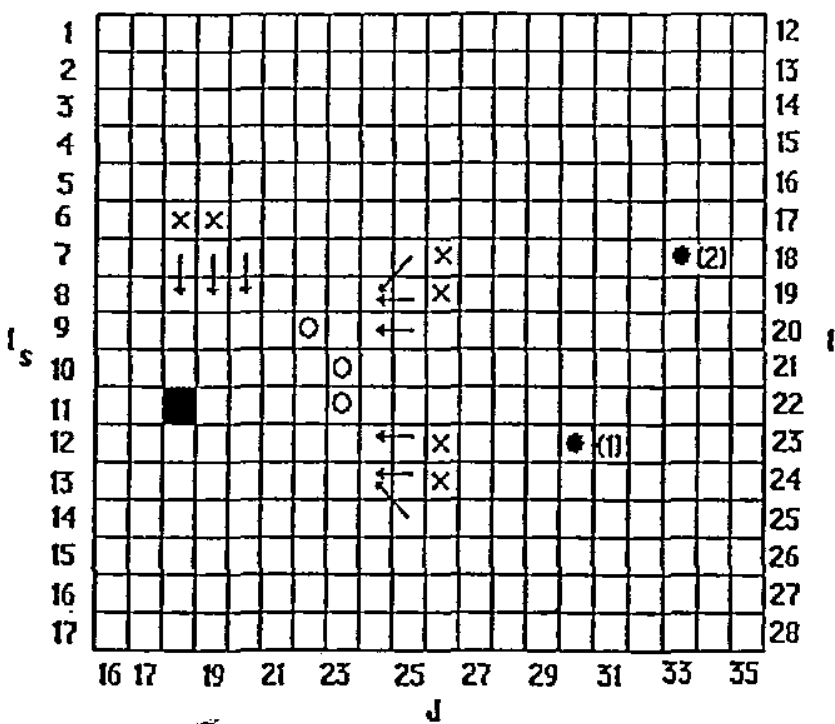

Legend:

unmanaged well

(1) layer 1

(2) layer 2

$\mathrm{x}$ active managed

injection well

O active managed extraction well

contaminant source

\& tight gradient

constraint

meter

o 153045

Figure 7 Location of optimal pumping wells and tight head-difference (gradient) constraints for Scenario 1. 
strategy will cause the desired gradients to occur. Transient simulation demonstrated that the gradient constraints would be satisfied 30 days after implementing the optimal pumping strategy (Figure 8). Figures 9 and 10 show the ultimate steady-state surface resulting from strategy implementation. Clearly, a groundwater divide has been formed between the plume and the supply well.

MOC is used to predict the pollutant transport that would result from strategy implementation. No contaminant moved past the injection wells.

Theoretical verification of the optimality of the computed strategy is beyond the scope of this document. However, many texts on operations research and linear programming assure the optimality of solutions to models having a linear objective function and constraints.

\section{Alternative Scenarios.}

Scenario 2. This scenario differs from the previous in the addition of a constraint forcing total injection to equal total extraction around the plume. Again, pumping from the two supply wells is not included in the total.

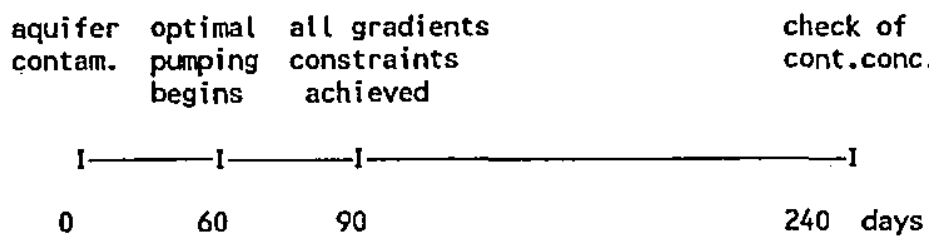

Figure 8 Time scale of Scenario 1.

$$
J \text { - column }
$$

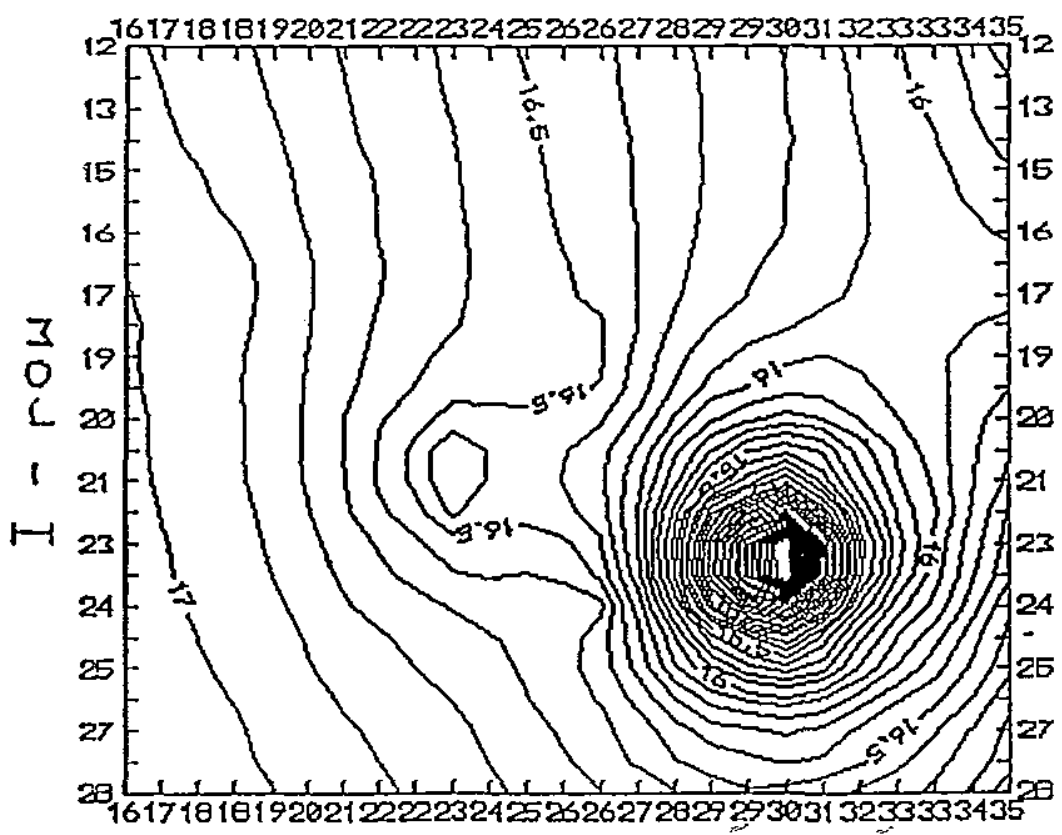

Figure 9 Subsystem potentiometric surface resulting from implementing the optimal pumping strategy for Scenario 1 (meters above MSL). 
: the trattegy the nene of : the cing pply

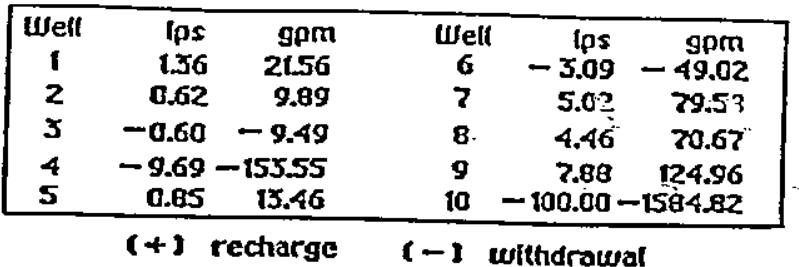

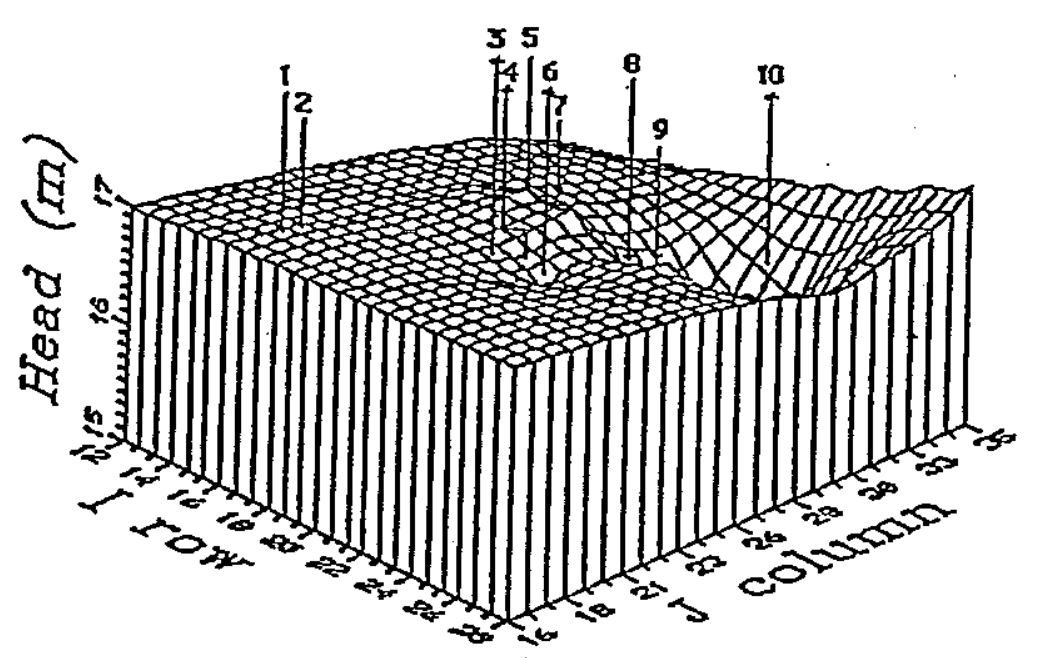

Figure 10 Subsystem potentiometric surface resulting after 6 months of optimal pumping for Scenario 1 (meters above MSL).

Results in Table 3 show an increase in extraction and a decrease in injection. Total pumping needed for plume containment increased slightly $(1.4 \%)$. This illustrates the phenomenon-increasing the number or restrictiveness of constraints does not improve the value of the objective function.

Although total pumping increased, one less extraction well is used in this strategy than in the previous (Table 4). The same number of gradient constraints are tight, but the locations of the tight gradient constraints differ slightly.

Scenario 3. This scenario demonstrates what might happen if involved managers have conflicting goals. It differs slightly from Scenario 1. In addition to controlling the plume, the agency wishes to extract more from layer 2 for water supply. Three new potential extraction wells are located in cells $(19,25),(20,25)$, and $(21,25)$, as if along a nearby road. Pumping is not permitted to change at the two initial supply wells.

Table 4 Numbers of Managed Wells that Will Pump Under the Optimal Strategies for the Tested Scenarios

\begin{tabular}{lcccc}
\hline & \multicolumn{2}{c}{$g($ extr. $)$} & & \\
\cline { 2 - 5 } Scenario & 1st Layer & 2nd Layer & $b$ (inj.) & $(g+b)$ total \\
\hline 1 & 3 & - & 6 & 9 \\
2 & 2 & - & 6 & 8 \\
3 & 4 & 3 & 14 & 21 \\
\hline
\end{tabular}


As a result, the objective function is altered to maximize new extraction from layer 2 while still minimizing the pumping in layer 1 needed to capture the plume. This is achieveci by assigning a negative sign to extraction from the supply wells, and minimizing:

$$
\sum_{j=1}^{J}\left(E_{j}\right)_{\text {st layer }}-\left(E_{j}\right)_{2 n d \text { layer }}+\sum_{k=1}^{K}\left(I_{k}\right)_{\text {st layer }}
$$

Since minimizing a negative number is the same as maximizing a positive number, minimizing negative extraction in layer 2 means maximizing that extraction.

Also added are new constraints imposed on vertical flow in cells $(21,21)$ and $(22,21)$. There, the head in the lower layer is forced to exceed that in the upper layer by $0.01 \mathrm{~m}$, preventing the downward migration of contaminant.

Figure 11 shows the resulting optimal injection and extraction well locations and tight gradient constraints. The optimal pumping strategy includes seven extraction wells and 14 injection wells. Although extraction of polluted water decreases, injection increases with respect to Scenario 1 (Table 3). Extraction of water for public supply increases by $31 \%$ above the unmanaged rate.

Although the gradient constraints are all satisfied by the optimal strategy, subsequent simulation demonstrated that the vertical gradient is reversed in some plume-containing cells in which the gradient was unconstrained. This illustrates that one must be careful in placing head or gradient control in appropriate locations. In practice, another optimization would be performed, using additional vertical head-difference or gradient constraints.

Processing Considerations. It is useful to consider the resources required to address optimization problems. First, the total computer time needed to solve an optimization problem is of

\section{$\mathrm{d}_{\mathrm{s}}$}

123456789101112814156617181920

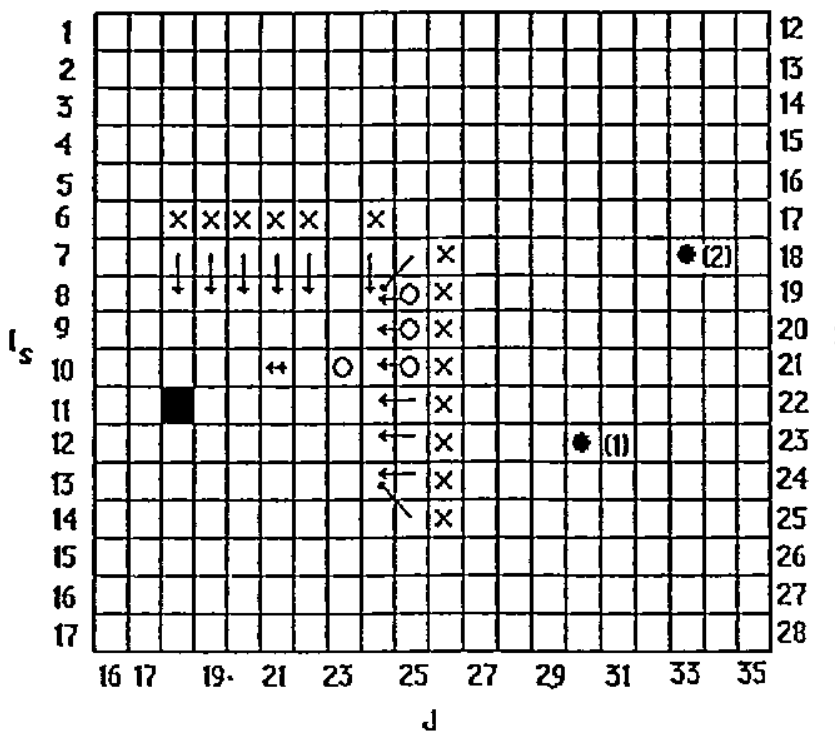

Legend:

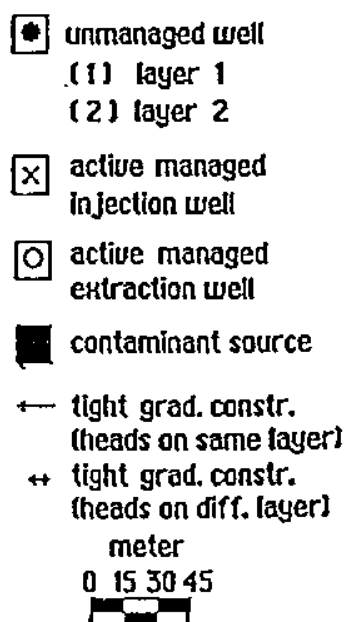

- unmanaged well

(1) layer 1

(2) layer 2

$x$ active managed injection well

O active managed extraction wel

contaminant source

- tight grad. constr. (heads on same layert

tight grad. constr. meads on diff. layer?

0153045

Figure 11 Location of optimal pumping wells and tight head-difference (gradient) constraints for Scenario 3 . 
2 murle

1 by as-

$22,21)$.

$\mathrm{m}$, pre-

ght gra-

4 injec-

spect to

the un-

ent sim-

cells in

ng head

be per-

optimi-

m is of

Table 5 Computer Time Required to Perform Each Activity for Scenario 1

\begin{tabular}{llr}
\hline Step & \multicolumn{1}{c}{ Software used } & Time (min) \\
\hline 1 & MODFLOW+STR (compute nonoptimal head) & 5.0 \\
2 & MOC (predict solute transport in a nonoptimal potent surface) & 35.0 \\
3 & PLUMAN (compute influence coefficients, formulate management model & 150.0 \\
& and determine optimal pumping strategy) & \\
4 & MODFLOW+STR (compute transient head response to optimal pumping) & 1.3 \\
5 & MOC (compute head and solute transport response to optimal pumping) & 8.0 \\
\hline
\end{tabular}

interest. Table 5 illustrates the time needed to address Scenario 1. Included stages use either the discussed simulation models or the PLUMAN code on a $386 \mathrm{PC}$ running at $33 \mathrm{MHz}$ and having 4 MB RAM. Time required for US/REMAX ${ }^{B}$ is comparable to that of PLUMAN, since it uses many of the same solution procedures.

Clearly, the stage of computing influence coefficients, arranging the optimization model, and calculating an optimal strategy is the most computationally intensive. For this scenario and stage, two steps can be distinguished. The first involves computing influence coefficients. The second is model organization and optimization problem solution.

Here, the step of generating influence coefficients requires by far the most time. This results because this act essentially involves one simulation of a modified MODFLOW +STR per potential pumping location. Since there are 31 potential pumping locations, 31 simulations are performed to develop the influence coefficients needed for the response matrix. The more decision variables (potential pumping rates), the more computer time involved in this step.

The step involving model formulation and calculation of the optimal strategy is fairly short. The time needed to perform the optimization is a function of the number of decision variables (potential pumping rates) and state variables (heads or gradients that must be constrained within the optimization model). The larger these numbers, the more time required.

Second, the size of the optimization problem being solved is of interest. For example, the special versions of US/WELLS ${ }^{\mathrm{D}}$ and US/REMAX ${ }^{\mathrm{B}}$ that are released in shortcourses are limited in the number of nonzero values they can have in the optimization formulation. (Even optimization algorithms that are not part of water management models are commonly limited either in the number of nonzeros or in the number of rows and columns in their constraint equations.)

By way of explanation, there is one row in the response matrix per head or gradient constraint equation per time step of constraint. There is one column in the matrix per decision variable. For a steady-state problem, total matrix size is the product of the number of control locations and the number of decision variables. The matrix contains one nonzero coefficient for each potential pumping location-head control location pair (per time step of active constraint).

For the steady-state Scenario 1 , there are $31 \times(22+31)$, or 1643 , nonzeros due to influence coefficients. There are also 31 nonzeros due to the weighting coefficients (even if they are 1 in value) assigned to decision variables in the objective function. Thus, the optimization model formulation for Scenario 1 employs almost 1700 nonzeros. (That of Scenario A using US/WELLS ${ }^{D}$ includes 919 nonzeros.) This number can be reduced significantly by considering injection in only every other cell on the plume periphery rather than in each cell. For example, if only 12 injection wells were considered, the number of nonzeros would be about $18 \times(22+18)+18$, or 738 . In addition to reducing problem size, this would significantly reduce computational time. 
Reducing the number of nonzeros below 1000 is important because that is the upper limit on problem size in the inexp, nnsive "special" versions of US/REMAX ${ }^{B}$ and US/WELLS ${ }^{D}$. If problem size increases beyond that, software price increases dramatically. The full professional versions of the software can addiess problems of virtually unlimited size.

\section{SUMMARY}

Use of simulation/optimization models can significantly aid management of groundwater contamination. It can speed the design process and reduce manpower costs. It can improve the produced remediation designs and reduce -smediation costs. It can easily address problems previously considered very difficult.

S/O modeling methods for groundwater flow management have been well established in research literature. Now, generally applicable S/O models are available for use on PCs. The discussed models, US/WELLS ${ }^{\mathrm{D}}$ and US/REMAX ${ }^{\mathrm{B}}$, use linear systems theory, influence coefficients, and superposition. These models can address a wide range of problems. Easy to use, they include all simulation and optimization algorithms needed to compute optimal strategies.

US/WELLS ${ }^{\mathrm{D}}$ and US/REMAX ${ }^{\mathrm{B}}$ are perfectly applicable to linear (confined) aquifer systems and can be applied to nonlinear systems. The former is most appropriate for fairly homogeneous aquifer and stream-aquifer systems. The latter can address complex heterogeneous multilayer stream-aquifer systems.

Increasing use of these PC-based S/O models is anticipated, especially as user-friendly options increase. Even the special versions of these models (released at shortcourses), can solve important real-world problems.

\section{REFERENCES}

1. Peralta, R. C., and Willardson, L. S., Optimizing ground water planning and management, U.S. Committee on Irrigation and Drainage Newsletter, April/June 1992, Denver, Colo., pp. 61-65.

2. Clarke, D., Microcomputer Programs for Groundwater Studies, Elsevier, New York, 1987.

3. Glover, R. E., and Balmer, G. G., River depletion resulting from pumping a well near a river, Trans. $A G U, 35(3)$, (1954).

4. McDonald, M. G., and Harbaugh, A. W., A modular three-dimensional finite-difference groundwater flow model, in Techniques of Water-Resources Investigations, U.S. Geological Survey, 1988, Chapter Al, Book 6.

5. Gorelick, S. M., A review of distributed parameter groundwater management modeling methods, Water Resources Res., 19(2), 305-319 (1983).

6. Morel-Seytoux, H. I., A simple case of conjunctive surface-ground-water management, Ground Water, 13(6) (1975).

7. Verdin, K. L., Morel-Seytoux, H. J., and Illangasekare, T. H., Users Manual for AQUISIM: FORTRAN IV Programs for Discrete Kernel Generation and for Simulation of Isolated Aquifer Behavior in 2 Dimensions, HYDROWAR Program, Colorado State Univ., Fort Collins, Colo., 1981.

8. Heidari, M., Application of linear systems theory and linear programming to groundwater management in Kansas, Water Resources Bull., 18(6), 1003-1013 (1982).

9. Illangasekare, T. H., Morel-Seytoux, H. J., and Verdin, K. L., A technique of reinitialization for efficient simulation of large aquifers using the discrete kernel approach, Water Resources Res., 20(11), 1733-1742 (1984).

10. Danskin,W. R., and Gorelick, S. M., A policy evaluation tool: management of a multisystem using controlled stream recharge, Water Resources Res., 21(11), 1731-1747 (1985).

11. Lefkoff, L. J., and Gorelick, S. M., AQMAN: Linear and Quadratic Programming Matrix Generator Using Two-Dimensional Ground-water Flow Simulation for Aquifer Management Modeling, U.S. Geological Survey Water-Resources Investigations Rep. 87-4061, 1987. 
12. Reichard, E. G., Hydrologic influences on the potential benefits of basinwide groundwater management, Water Resources Res., 23(1), 77-91 (1987).

13. Ward, R. L., and Peralta, R. C., EXEIS-Expert Screening and Optimal Extraction/Injection Pumping Systems for Short-Term Plume Containment, Rep. ESL-TR-87-57, Air Force Engineering and Services Center, Tyndall AFB, Fla., 1990.

14. Willis, R., and Finney, B., Optimal control of nonlinear groundwater hydraulics: theoretical development and numerical experiments, Water Resources Res., 2I(10), 1476-1482 (1985).

15. Aly, A. H., and Peralta, R. C., US/WELLS ${ }^{D}$, Extraction/Injection Well System for Optimal Groundwater Management: User's Manual, Biological and Irrigation Eng. Dept., Utah State Univ., Logan, Utah, 1992.

16. Peralta, R. C., Aly, A. H., Suguino, H. H., Belaineh, G., and Miyojim, M., US/REMAX ${ }^{B}$, Utah State Model for Optimizing Management of Stream-Aquifer Systems Using the Response Matrix Method: User's Manual, Version 1.05, Biological and Irrigation Eng. Dept., Utah State Univ., Logan, Utah, 1992.

17. Prudic, D. E., Documentation of a Computer Program to Simulate Stream-Aquifer Relations Using a Modular, Finite-Difference, Ground-Water Flow Model, U.S. Geological Survey, Open-File rep. 88-729, 1989.

18. Suguino, H., and Peralta, R. C., PLUMAN: A Decision Support System for Optimal Groundwater Contaminant Plume Management: User's Manual, Version 1.0, Software Eng. Div., Dept. Biological and Irrigation Eng., Utah State Univ., Logan, Utah, 1992.

19. Konikow, L. F, and Bredehoeft, J. D., Computer model of two-dimensional solute transport and dispersion in ground water, in Techniques of Water Resources Investigations, USGS, Washington, D.C., 1984, Book 7, Chapter C2.

20. Suguino, H., A decision support system for optimal groundwater contaminant plume management, Ph.D. dissertation, Dept. Agricultural and Irrigation Eng., Utah State Univ., Logan, Utah, 1992.

21. Todd, D. K., Groundwater Hydrology, Wiley, New York, 1980.

\section{ADDITIONAL READING}

Colarullo, S. J., Heidari, M., and Maddock, T., III (1984). Identification of an optimal groundwater management strategy in a contaminated aquifer, Water Resources Bull., 20(5), 747-760.

Gharbi, A. (1991). Optimal groundwater quantity and quality management with application to the Salt Lake Valley, Ph.D. Dissertation, Dept. Agricultural and Irrigation Eng., Utah State Univ., Logan, Utah.

Peralta, R. C., Killian, P. J., Yazdanian, A., and Kumar, V. (1989). SSTAR Users Manual; Rep. IIC-89/3, International Irrigation Center Utah State Univ., Logan, Utah. 


\section{UTAH STATE UNIVERSITY LOGAN, UTAH 84322-4810}

Utah Agricultural Experiment Station

Office of the Director

(801) $750-2206$

Fax (801) 750-3321

Dialcom Address AGS2300

\section{MEMORANDUM}

TO:

Richard Peralta

17

FROM:

H. Paul Rasmussen

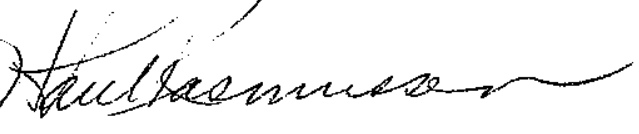

DATE :

December 13,1993

SUBJECT: Request for Payment of Reprints of Book Chapter

The policy of the UAES is not to pay for publication nor reprint costs on book chapters as they do not normally contain original data and are not part of an Experiment station Project. I have read this manuscript and find that it is in final galley and has not been through the UAES process for consideration of funding.

At this point it is usually not possible to recognize the UAES as is required for our participation in publication costs. I therefore have no alternative but to deny your request for funding of reprints.

In the future if you choose to have Experiment station support for your work please see that it comes to the UAES Information office for review and assignment of a UAES number. All manuscripts published through my office must have both a number and the statement of support from the UAES.

Based on our telephone conversation I trust that we have cleared up the procedure we operate under for support of published material by faculty members who have at least partial appointments through the UAES.

If you have any further questions please let me know.

pc/ Kurt Gutknecht

84.93

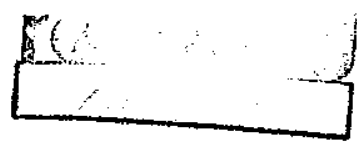




\section{OFFPRINT ORDER FORM}

marcel dekker, inc.

270 MAOISON AVENUE, NEW YORK, NY 10016/212 696-9000 PUBLISHERS

TELEX: 421419 MARDEEK

FAX: 212-685-4540

EDITOR: WISE/TRANTOLO

ARTICLE: PC SOFTWARE FOR OPTIMIZING GROUNDWATER CONTAMINAT ...

PAGES: $597-618$

CHAPTER: 29

TOTAL PAGES: 22

AUTHORS: RICHARD PERALTA

\section{TO RECEIVE OFFPRINTS THIS AREA MUST BE COMPLETED}

\section{BII \\ $\mathrm{SPL}$}

RECIPIENT

NAME OF COMPANY OR INSTITUTION

Utah State Univ.

DEPARTMENT

FAX \#

BUILDING OR LOCATION OTHER THAN STREET ADDRESS (IF APPLICABLE)

STREET ADORESS

CITY

STATE
SHIP OFFPRINTS TO:

SPECIFIC RECIPIENT

NAME OF COMPANY OR INSTITUTION

DEPARTMENT PHONE \# $\quad$ FAX \#

BUILDING OR LOCATION OTHER THAN STREET ADDRESS (IF APPLICABLE)

STREET ADDRESS

CITY

STATE

ZIP CODE

INDICATE ON THIS FORM IF OFFPRINTS ARE TO BE PAID BY AN INSTITUTION. IF SO, SHIPMENT WILL BE MADE ONLY WITH A FORMAL INSTITUTIONAL PURCHASE ORDER. THIS PURCHASE ORDER SHOULD STATE THAT THE POSTAGE \& HANDLING CHARGE WILL BE ADDED TO THE LIST PRICE OF THE OFFPRINTS. CHECK APPROPRIATE BOX.

PURCHASE ORDER IS ATTACHED

(PURCHASE ORDER NO.
PURCHASE ORDER WILL FOLLOW

INVOICE CONTRIBUTOR

SUt. E MAIL FOR NON-DOMESTIC SHIPMENTS MAY TAKE 6 MONTHS. IF YOU WISH TO RECEIVE YOUR PRINTS VIA AIR MAIL, PLEASE INDICATE AT RIGHT. (YOU WILL BE BILLED ACCORDINGLY).

NUMBER OF OFFPRINTS (IN MULTIPLES OF 100) TO BE BILLED AND SHIPPED 


\section{OFFPRINT ORDER FORM}

270 MADISON AVENUE, NEW YORK, NY 10016/212 696-9000 PUBLISHERS

TELEX: 421419 MARDEEK

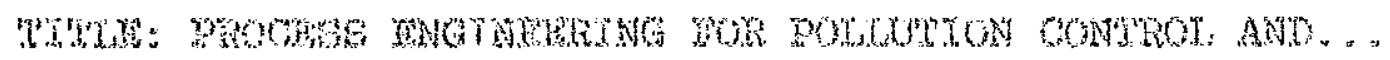

Whot: WST/RAWTH

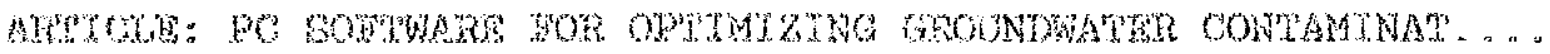

sas: $597-6 \mathrm{~s}$

CHAPTER: 20

TOWA PAOES: 22

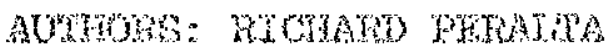

\section{EIf \\ $\mathrm{SP}$} RECIPIENT

TO RECEIVE OFPPRINTS THIS AREA MUST BE COMPLETED

NAME OF COMPANY OR INSTITUTION

(f) COMPAN ORINSTITUTON

DU PHONE \#

FAX \#

BUILDING OR LOCATION OTHER THAN STREET ADDRESS (IF APPLICABLE)

STREET ADDRESS

CITY

STATE
SHITOHFRINSTO

SPECIFIC RECIPIENT

NAME OF COMPANY OR INSTITUTION

DEPARTMENT

PHONE \#

FAX \#

BUILDING OR LOCATION OTHER THAN STREET ADDRESS (IF APPLICABLE)

STREET ADDRESS

$\mathrm{CITY}$

STATE

ZIP CODE

INDICATE ON THIS FORM IF OFFPRINTS ARE TO BE PAID BY AN INSTITUTION. IF SO, SHIPMENTWILL BE MADE ONLYWITH A FORMAL INSTITUTIONAL PURCHASE ORDER. THIS PURCHASE ORDER SHOULD STATE THAT THE POSTAGE \& HANDLING CHARGE WILL BE ADDED TO THE LIST PRICE OF THE OFFPRINTS. CHECK APPROPRIATE BOX.

$\square$ PURCHASE ORDER IS ATTACHED

(PURCHASE ORDER NO.

SUF. E MAIL FOR NON-DOMESTIC SHIPMENTS MAY TAKE 6 MONTHS. IF YOU WISH TO RECEIVE YOUR PRINTS VIA AIR MAIL, PLEASE INDICATE AT RIGHT. (YOU WILL BE BILLED ACCORDINGLY). 


\section{marcel dekker, inc.}

70 Madison Ave., New York, NY. $10016 \cdot(212) 696-9000$

Melex: 421419 MARDEEK · Telefax (212) 685-4540

\section{Direct Dial Extension:}

$1.201 / 9$

F: w w Uिस:

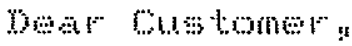

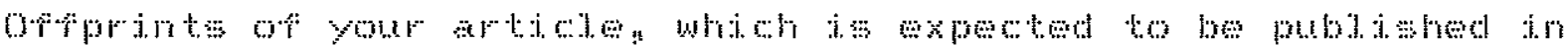

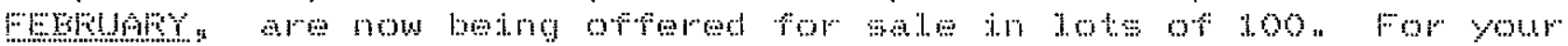

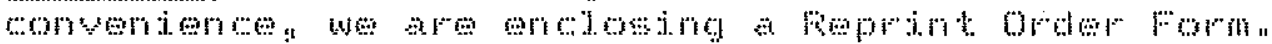

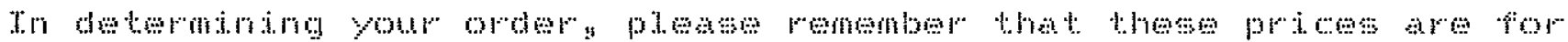

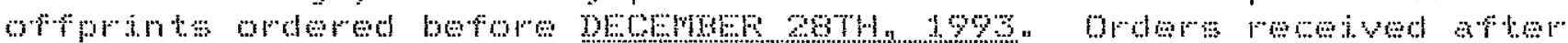

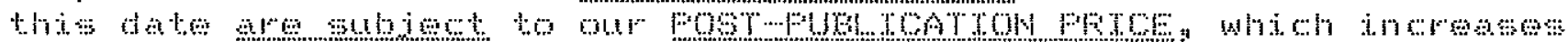

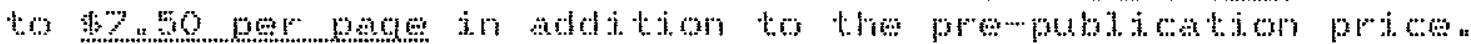

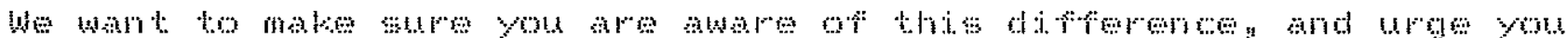

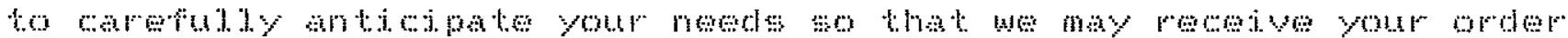

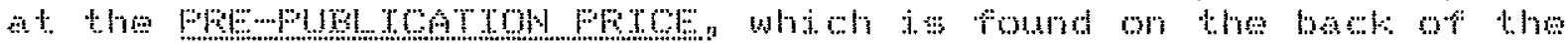

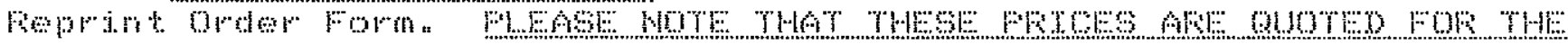
HHEF OF

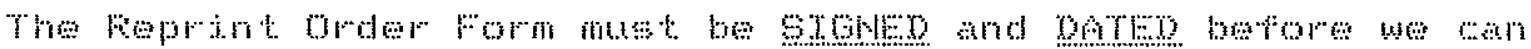

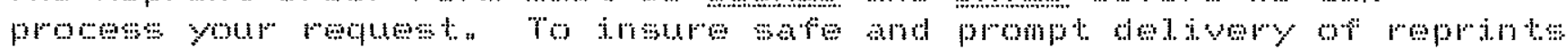

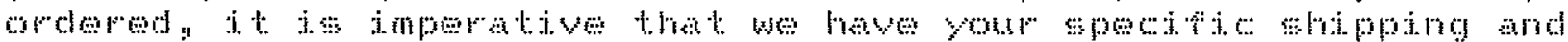

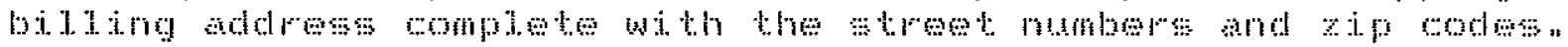

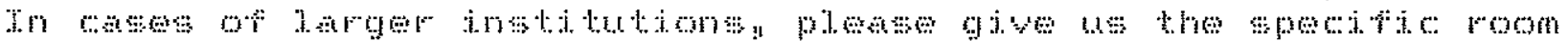

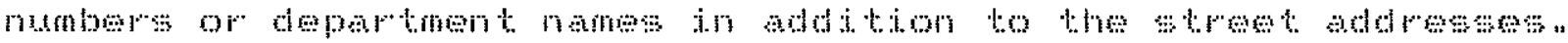

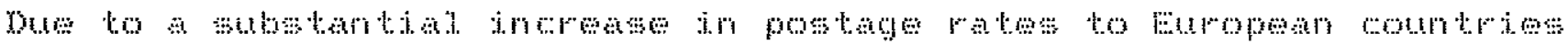

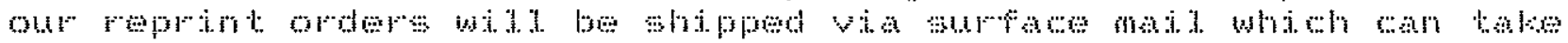

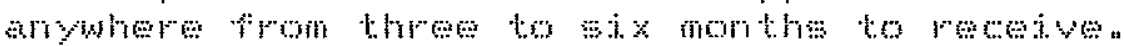

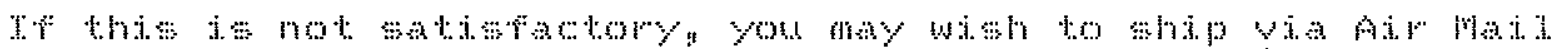

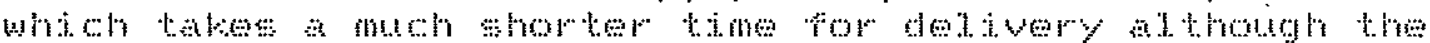

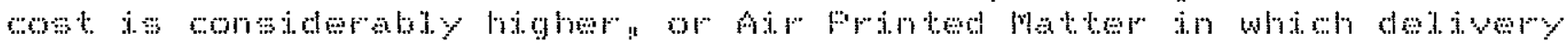
t.

1.

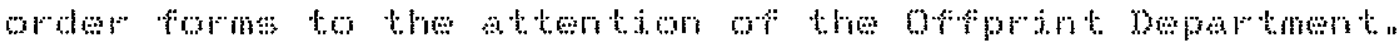

$\sin m \%$ i.

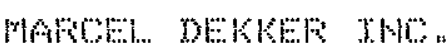

(\%)

Publishers New York - Basel · Hong Kong 


\section{Utah Agricultural Experiment Station PUBLICATION APPROVAL FORM}

The Experiment Station will pay a maximum of $\$ 500$ for page charges and a maximum of $\mathbf{1 0 0}$ reprints (without covers) only if a manuscript has been assigned a journal paper number. Attach one double-spaced copy of the manuscript to this form for review. The manuscript must also include an acknowledgement of support* by the Utah Agricultural Experiment Station.

(Please type or print legibly)

Title PC Software for optinizing groudwate- contaminant plump capture and containment

Authors Peralta, R.C., Suguino, $H$ and $A I_{y}, A . H$.

Proposed Place of Publication Bosk. Process Ensineeris for Pollution Cantrol and Report or Project No. UTA00807 Fund Waste Minimizution

(Costs of grant-supported publication should come out of grant funds.)

Estimated page charges for your paper.

(The manuscript must be accompanied by a copy of the journal's fee schedule or it will be returned.)

If reprints are not included in the page charges what is the cost for 100 reprints?

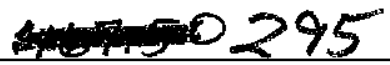

If ordering more than 100 reprints, please give the account number for additional copies.

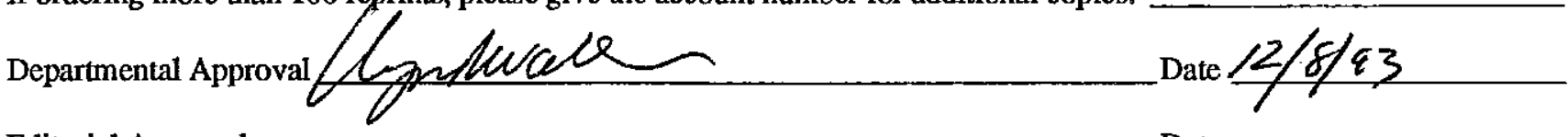

Editorial Approval

Date

(Please allow several days for editing and review. The author should employ bibliographical citations, abbreviations and manuscript from recommended by the journal.)

Director's Approval

Date

Submit papers to the journal after approval. The manuscript must be resubmitted for Experiment Station approval if publication is delayed for more than 12 months from original submission date.

Submit reprint orders to the UAES Information Office for payment. Reprints will be delivered directly to the author. Four (4) copies should be sent to the UAES Information Office upon receipt. We will NOT pay for reprints that have not been ordered through the Information Office or that have not been assigned a journal paper number. Galley proofs are usually returned to the journal separately from orders to avoid delays.

\section{UAES Information Office \\ Utah State University \\ Logan, UT 84322-4845 \\ (801) 750-2206}

*This research was supported by the Utah Agricultural Experiment Station, Utah State University, Logan, Utah 84322-4810. Approved as journal paper no. 


\section{PRINT \\ ARDER FORM}

\section{marcel dekker, inc.}

270 MADISON AVENUE, NEW YORK, NY 10016/212 696-9000 PUBLISHERS

TELEX: 421419 MARDEEK

SBN PREFIX 8247INENDOR I.D. NO. 13-198-8531 FAX: 212-685-4540

TITLE: PROCESS ENGINEERING FOR POLLUTION CONTROL AND...

EDITOR: WISE/TRANTOLO

ARTICLE: PC SOFTWARE FOR OPTIMIZING GROUNDWATER CONTAMINAT....

PAGES: $597-618 \quad$ CHAPTER: $29 \quad$ TOTAL PAGES: 22

AUTHORS: RICHARD PERALTA

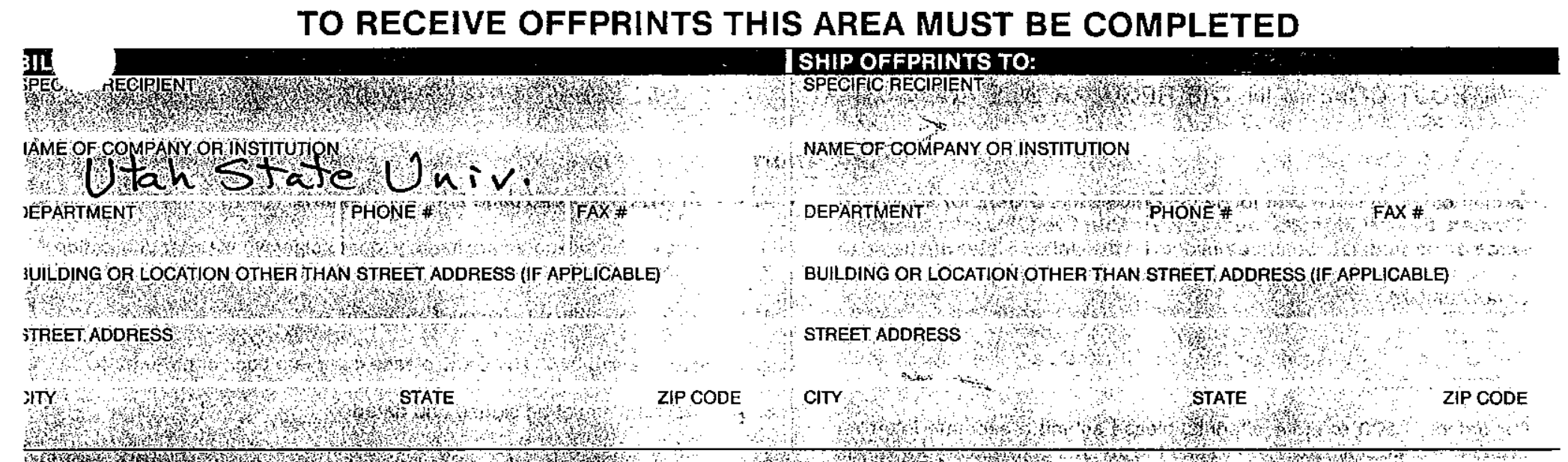

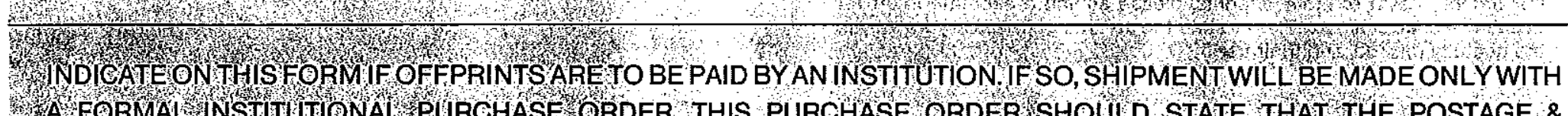
2. TORMAL NSTIIUTIONAL PURGHASE ORDER THIS PURCHASE ORDER SHOULD STATE THAT THE POSTAGE \& 1. HANOING GHARGE WIIL BE ADDED TO THE LIST PRICE OF THE OFPRRINTS CHECK APPROPRIATE BOX

Fon.

PUREHASEORDER IS ATIACHED

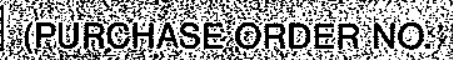

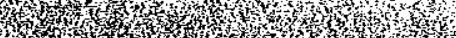

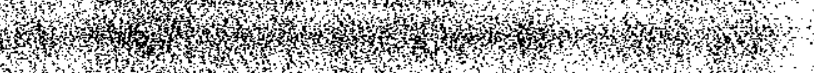

SIGNATURE IS REOUIRED

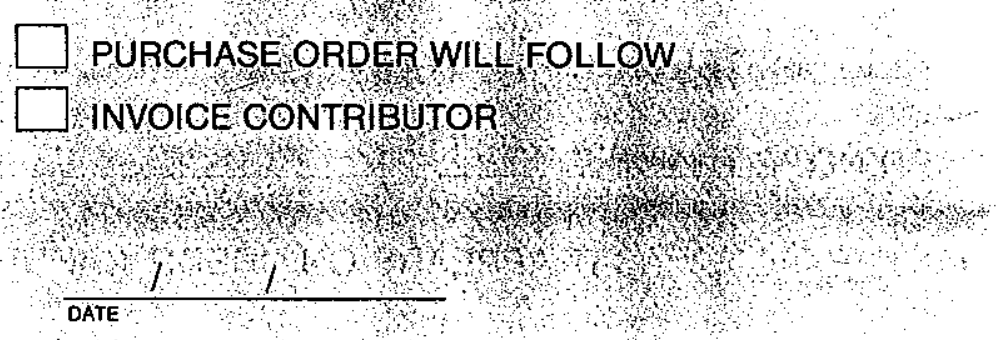


PRICE LIST FOR OFFPRINTS (BASED UPON NUMBER OF PAGES PER ARTICLE IN LOTS OF 100 COPIES)

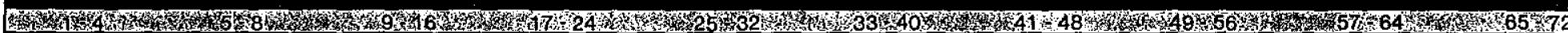

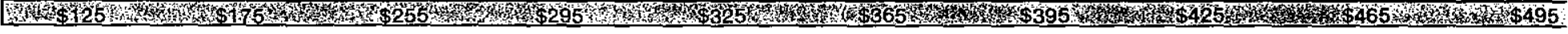

POSTAGE AND HANDLING CHARGES FOR PURCHASED OFFPRINTS WILL BE ADDED TO THE LIST PRICE.

THESE ARE PREPUBLICATION PRICES, AND APPLY ONLY TO ORDERS RECEIVED BEFORE THE PUBLICATION GOES TO PRESS. WE SUGGEST YOU ORDER YOUR MAXIMUM REQUIREMENTS AT THIS TIME. THEY ARE FOR OFFPRINTS WITHOUT COVERS IN THE REGULAR SIZE AND FORMAT. PRICES ARE SUBJECT TO CHANGE WITHOUT NOTICE. CANCELLATIONS AND RETURNS OF OFFPRINT ORDERS CANNOT BE ACCEPTED.

\section{IMPORTANT}

1. Offprint orders must be sent to Marcel Dekker, Inc. Orders for articles in "Camera Ready" journals must arrlve within two (2) weeks of acceptance of manuscript. Contributors outside the United States are urged to send offprint orders by Air Mail. (International Air Mail must have phone or fax number).

4. Return first page. Keep page 2 for your records.

5. Offprints will be mailed approximately four to eight weeks after public of the Journal/Book.

6. We will lnvoice within 4 weeks of shipment

2. Please type all instructions on this form. If necessary use supplemental sheets and attach.

7. If you are paying by Credit Card, please complete back of order forn

8. All order forms must be signed and dated.

3. For orders of 500 or more offprints, please submit a separate letter requesting a price estimate. Please state the number of pages in your article, the quantity desired, and their use.

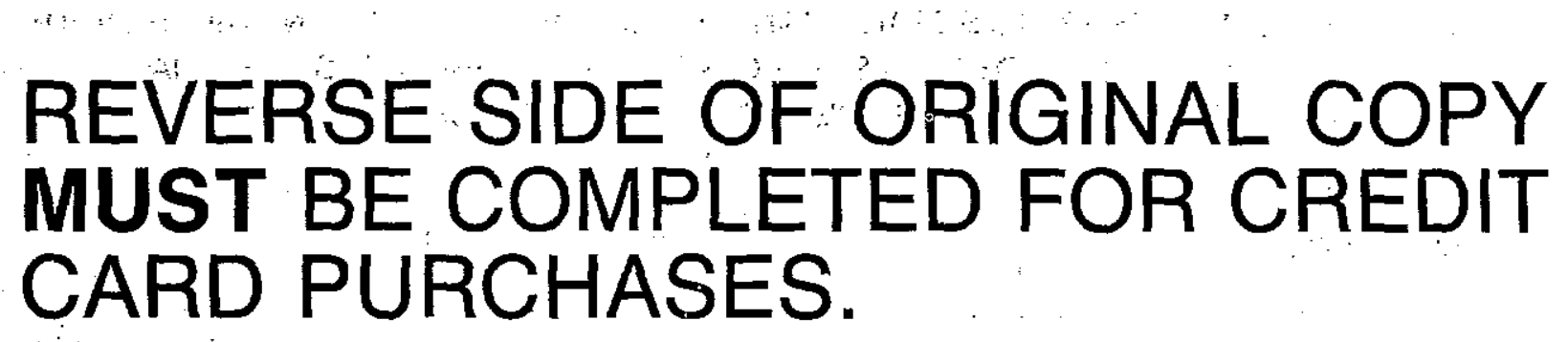




\section{arcel dekker, inc. \\ 

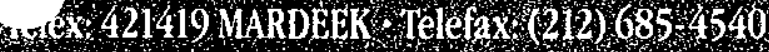

\section{Direct Dial Extension:}

\section{t. $2 / 01 / 93$}

अ w w5

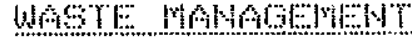

Мж

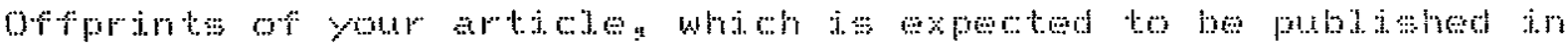

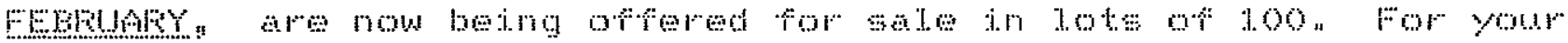

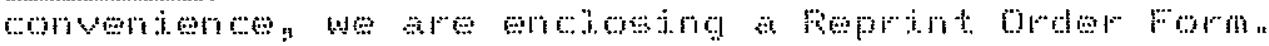

fo detem

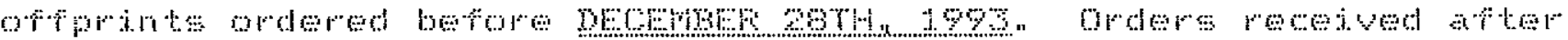

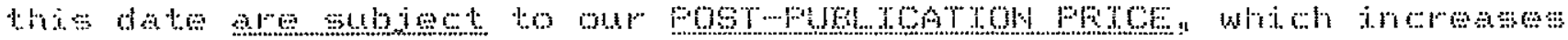

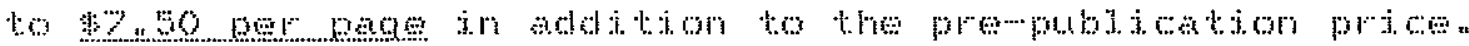

we wht to male

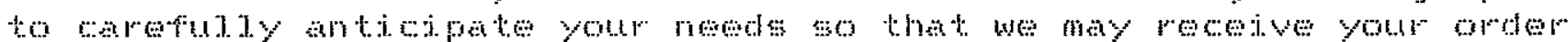

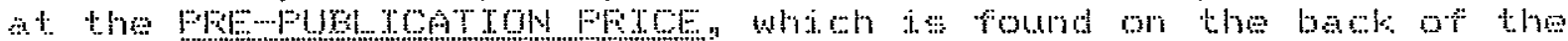

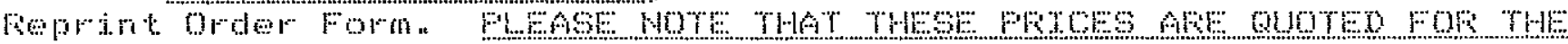

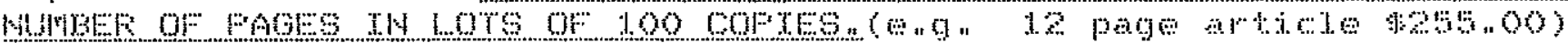

The weprint omer Fom nust be

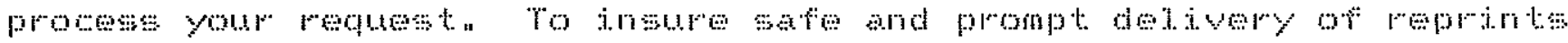

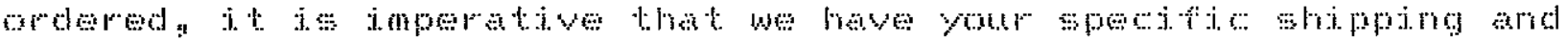

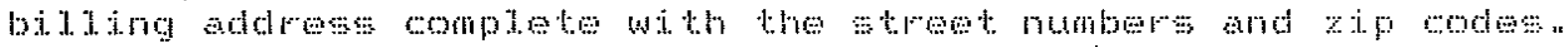

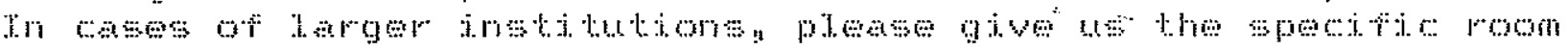

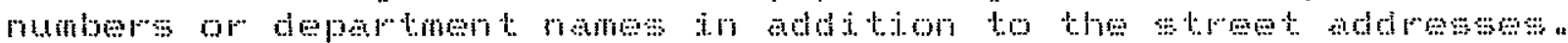

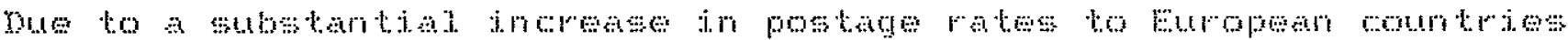

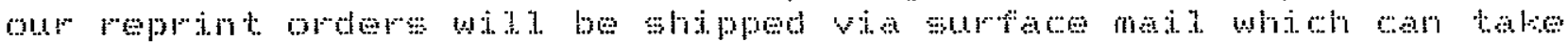

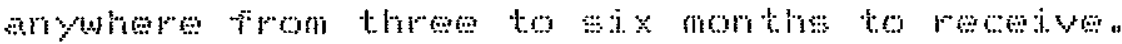

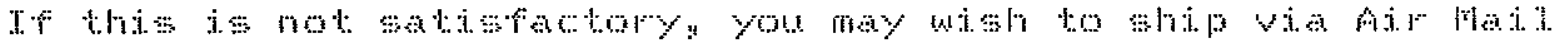

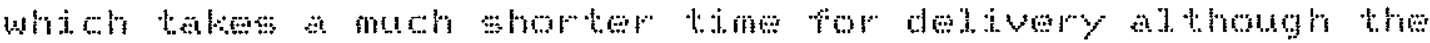

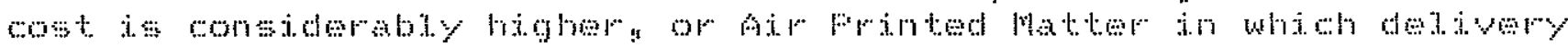

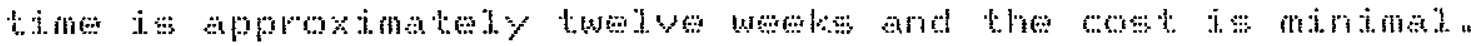

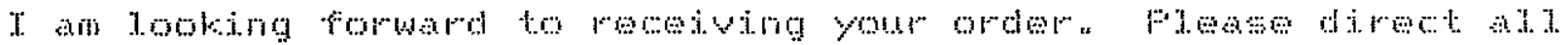

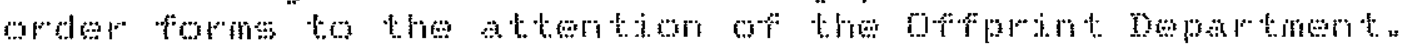

i.

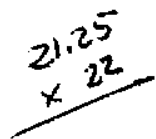

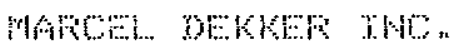

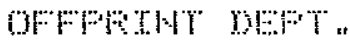




\section{arcel dekker, inc.}

OOMadison Ave, New York, NY 10016 \%(212)-696-9000

elex:421419MARDEEK Tele ax (212) 685:4540

Direct Dial Extension:

PRODUCTION EDITOR Eric Stannard

Ext. 312

Title

Process...

Au/Ed

Wise/'l'rantolo

Date

$8,26 / 1993$

Chapter(s)

29

Pages

$$
597-618
$$

Dear Dr. Peralta:

Enclosed please find the master proofs for the material listed above, along with the corresponding manuscript. Also enclosed, if applicable, is a copy of the contributors list showing your name and affiliation as they will appear in the book; please confirm that your entry is correct and return the page along with the proofs.

Read the proofs carefully against the manuscript. This is the last time you will see the proofs, and we will not be reading them in house. If there are copyeditor's queries in the margins of the manuscript, please reply by making the appropriate changes on the proofs. Mark corrections neatly and in a distinctive color.

Restrict your changes to corrections of typographical and factual errors. This is not the time to rewrite. Please understand that it may not be possible to accommodate any changes you make beyond correction of errors; alterations at this stage are expensive, time-consuming, and likely to introduce additional errors. Also, if you are late in returning your proofs, we may not be able to make any of your changes.

Check the placement and orientation of each figure. (If you see empty spaces where there should be art, we will be sending you proofs of those figures later so you can verify their position. Please do not let this delay your proofreading.)

Thank you very much for your cooperation.

Return all the material-proofs, manuscript, contributors page-to my attention within 10 days of receipt. If you expect to be delayed, or have any questions, please call or fax me.

Sincerely,

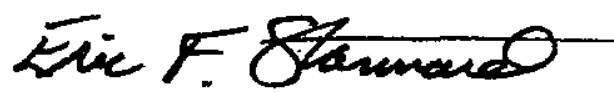

Eric F. Stannard

Production Editor 


\section{Index Set}

Circle key words on the proof. This faclitites organizing the index entrles with the appropriate page numbers. Please circle the key words in a distinctive color. If the topic appears on following pages, it would be belpful to make a note of the inclusive page numbers in the
margin.

Please return the index set within 10 days of receipt to:

Dr. Debra J. Trantolo

Cambridge Scientific Inc.

$$
\begin{array}{r}
(617) 484-3217 \\
373-2992
\end{array}
$$

195 Common st.

Belmont, MA 02178 


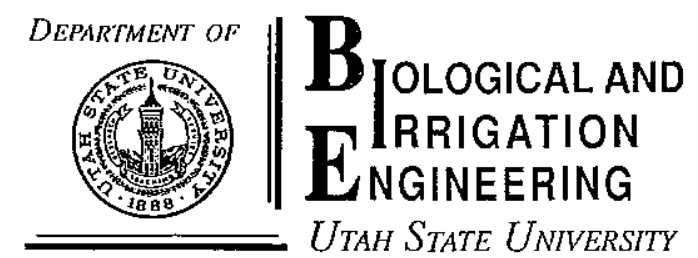

Logan, Utah 84322-4105, U.S.A.

Telephone: (801) 750-2785

Fax: (801) 750-1248

September 16,1993

Dear Dr. Trantolo:

Enclosed please find the revised copy of the master proofs for chapter 29 (pages 597-618) of the book you are currently editing. Few corrections are marked (in red) in pages 600, 601, and 606 . The following is a list of the changes:

1. Page 600: replace "depletion" with "pumping" in the $10^{\text {th }}$ line from the bottom of the page.

2. Page 601: replace "0.X" with "1.X" in Table 2.

3. Page 606: change "US/REMAX" to be "US/REMAX", i.e., change the superscript (first paragraph).

Thank you very much for your cooperation.

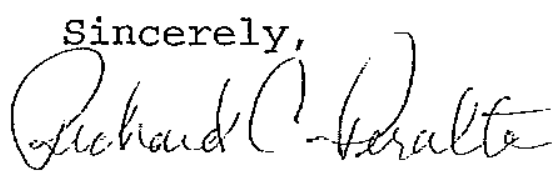

Richard C. Peralta

Professor, DBIE. 


\section{marcel dekker, inc. \\ 270 Madison Ave, New York, NY 10016 - (212) 696-9000 \\ Telex 421419 MARDEEK Telefax: (212) 685-4540}

Direct Dial Extension:

PRODUCTION EDITOR Eric Stannard

Ext. 312

Title Process...

Au/Ed Wise/'I'rantolo

Date $8 \longdiv { 2 6 / 1 9 9 3 }$

Chapter(s)

Pages

\section{9}

$597-618$

Dear Dr. Perhlta!

Enclosed please find the master proofs for the material listed above, along with the corresponding manuscript. Also enclosed, if applicable, is a copy of the contributors list showing your name and affiliation as they will appear in the book; please confirm that your entry is correct and return the page along with the proofs.

Read the proofs carefully against the manuscript. This is the last time you will see the proofs, and we will not be reading them in house. If there are copyeditor's queries in the margins of the manuscript, please reply by making the appropriate changes on the proofs. Mark corrections neatly and in a distinctive color.

Restrict your changes to corrections of typographical and factual errors. This is not the time to rewrite. Please understand that it may not be possible to accommodate any changes you make beyond correction of errors; alterations at this stage are expensive, time-consuming, and likely to introduce additional errors. Also, if you are late in returning your proofs, we may not be able to make any of your changes.

Check the placement and orientation of each figure. (If you see empty spaces where there should be art, we will be sending you proofs of those figures later so you can verify their position. Please do not let this delay your proofreading.)

Thank you very much for your cooperation.

Return all the material-proofs, manuscript, contributors page-to my attention within 10 days of receipt. If you expect to be delayed, or have any questions, please call or fax me.

Sincere1y,

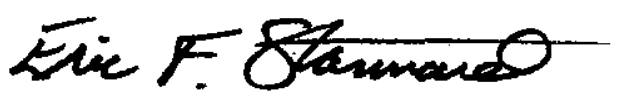

Eric F. Stannard

Production Editor 
Circle key words on the proof. Th1s facllitates organizing the index entries vith the appropriate page numbers. Please circle the key words in a distinctive color. If the topic appears on following pages, $1 t$ would be helpful to make a note of the inclusive page numbers in the margin.

Please return the index set within 10 days of receipt to:

Dr. Debra J. Trantolo

Cambridge Scientific Inc.

$$
\begin{array}{r}
(617) 484-3217 \\
373-2992
\end{array}
$$

195 Common St.

Belmont, MA 02178 


\title{
29 \\ PC Software for Optimizing Groundwater Contaminant Plume Capture and Containment
}

\author{
Richard C. Peralta, Herminio H. Suguino, and Alaa H. Aly \\ Uah State University \\ Logan, Utah
}

\section{INTRODUCTION}

Simulation/optimization (S/O) models can be used to speed the process of computing desirable groundwater pumping strategies for plume management. They make the process of computing optimal strategies fairly straightforward and can help minimize the labor and cost of groundwater contaminant cleanup.

Differences between S/O models and the simulation (S) models currently used by over $98 \%$ of practitioners are discussed in Section II [1], followed by an overview of the two most common forms of groundwater management S/O models, their strengths and limitations, in Section III. In Section IV, currently available PC-based $S / O$ models are discussed, and the ways in which they would be applied to representative situations are illustrated. Included is US/ WELLS ${ }^{\mathrm{D}}$, an easy-to-use deterministic model that requires minimal data but will address aquifer and stream-aquifer systems where the analytical solutions of Theis [2] and Glover and Balmer [3] are appropriate. Also included is US/REMAX ${ }^{\mathrm{B}}$, appropriate for heterogeneous, multilayer systems. To ease use, that code accepts data in format readable by MODFLOW [4], the most widely used flow simulation model in the United States today.

These two S/O models are selected because they are the only ones we are aware of that (1) are available for use on PCs, (2) include with them the optimization algorithms necessary for solution, and (3) use superposition. As explained later, these characteristics make them especially useful for plume management by consultants and water resource managers.

\section{COMPARISON BETWEEN COMMONLY USED SIMULATION MODELS AND SIMULATION/OPTIMIZATION MODELS}

A simulation/optimization (S/O) model contains both simulation equations and an operations research optimization algorithm. The simulation equations permit the model to appropriately represent aquifer response to hydraulic stimuli and boundary conditions. The optimization al- 
gorithm permits the specified management objective to serve as the function driving the search for an optimal strategy. The model computes a pumping strategy that minimizes (or maximizes) the value of the objective function.

Table 1 shows generic inputs and outputs of the generally used simulation (S) model and those of an S/O model. The normal $S$ models compute aquifer responses to assumed (input) boundary conditions and pumping values. Using such models to develop acceptable pumping strategies can be tedious and involve much trial and error. For example, simulated system response to an assumed pumping strategy might cause unacceptable consequences. In that case, the user must assume another pumping strategy, reuse the model to calculate aquifer response, and recheck for acceptability of results. This process of assuming, predicting, and checking might have to be repeated many times. The number of repetitions increases with the number of pumping locations and control locations (places where acceptability of system response must be evaluated and ensured).

When using an $S$ model, as the number of possible pumping sites increases the likelihood that the user has assumed an "optimal" strategy decreases. Also, as the number of restrictions on acceptable system response to pumping increases, the ability of the user to assume an optimal strategy also decreases. Assuming a truly optimal strategy becomes impractical or nearly impossible as problem complexity increases. There are too many different possible combinations of pumping values. Furthermore, even if the computation process is automated in a computer program, the act of checking and ensuring strategy acceptability becomes increasingly painful as the number of control locations becomes large. In essence, it becomes impossible to compute mathematically optimal strategies for complicated groundwater management problems using $S$ models.

Alternatively, S/O models directly calculate the best pumping strategies for the specified management objectives and ensure that the resulting heads and flows lie within prespecified limits or bounds (Table 1). The upper and lower bounds reflect the range of values that the user considers acceptable for cell pumping rates and resulting heads. The model automatically considers the bounds while calculating optimal pumping strategies. The user might choose to use lower bounds on pumping at currently operating public supply wells. He/she might choose to limit pumping at the upper end of the range, depending on hardware availability or legal restrictions. The user might impose lower bounds on head, at a specific distance below current water levels or above the base of the aquifer. Upper bounds might be the ground surface or a specified distance below the ground surface.

Assume, for example, a situation in which a planning agency is attempting to determine the least amount of groundwater pumping needed to capture a contaminant plume and the locations where it should be pumped, i.e., the spatiai distribution of the withorawais and injections. If a pumping strategy is not implemented to achieve capture, the contaminant will reach public supply wells, resulting in litigation and undesirable costs.

Table 1 Comparison Between Simulation and Simulation/Optimization Models

\begin{tabular}{|c|c|c|}
\hline Model type & Input values & Computed values \\
\hline Simulation (S) & $\begin{array}{l}\text { Some boundary flows } \\
\text { Some boundary heads } \\
\text { Pumping }\end{array}$ & $\begin{array}{l}\text { Some boundary flows } \\
\text { Heads at "variable" head cells }\end{array}$ \\
\hline Simulation/optimization (S/O) & $\begin{array}{l}\text { Some boundary flows } \\
\text { Some boundary heads } \\
\text { Bounds on pumping, } \\
\text { heads, flows }\end{array}$ & $\begin{array}{l}\text { Optimal boundary flows } \\
\text { Optimal heads at "variable" head cells } \\
\text { Optimal pumping }\end{array}$ \\
\hline
\end{tabular}


An S/O model can be used to directly calculate an optimal pumping strategy for the goal of minimizing the pumping needed to capture the plume without causing unacceptable consequences. For example, assume that no injection mounds should reach the ground surface and that no drawdowns should exceed $2 \mathrm{~m}$. In addition, assume that potentiometric surface gradients near the plume should be toward the plume source.

The S/O model will directly calculate the minimum total pumping rate needed and will identify how much should be pumped from each pumping location. The potentiometric surface heads and gradients that will result from the optimal pumping will lie within the bounds specified initially (Table 1). In other words, future heads will not reach the ground surface, future heads will not be more than $2 \mathrm{~m}$ below current heads, and final gradients will be toward the contaminant source. Thus, the very first optimal pumping strategy computed by an S/O model will satisfy all specified management goals.

\section{COMMON S/O MODELING APPROACHES AND LIMITATIONS}

Most S/O models employ either an embedding or a response matrix approach for representing system (head) response to pumping [5]. Embedding models contain finite-difference or finiteelement equations embedded directly as constraints. In a finite-difference embedding model, head and pumping values (or other flows) must be computed for each time step at each cell. This is a very useful approach for those situations in which (1) pumping should be a decision variable at most cells, (2) head must be constrained in a high proportion of cells, and (3) either a steady-state strategy should be developed or there need be very few time steps. It is not as desirable if there are relatively few pumping cells and control points or if many time steps are needed. Thus, cmbedding models have been mainly used for steady-state regional planning and for small hypothetical problems.

Response matrix S/O models use linear systems theory and superposition with influence coefficients (e.g., [6]-[14] and many others). The matrix containing the influence coefficients and superposition (summation equations) is termed the response matrix. Response matrix (RM) models use a two-step process. First, normal simulation (analytical or numerical) is used to calculate system response to assumed unit stimuli. Then optimization is performed by an $\mathrm{S} / \mathrm{O}$ model that includes summation equations (discretized forms of the convolution integral).

Response matrix models are ideal for transient management situations. They require constraint equations for only those specific cells and time steps at which head or flow (other than pumping) must be restricted during the optimization. To predict system response to the optimal strategy at locations and times other than those constrained in the S/O model, an external simulation model is used after the optimization.

Regardless of the simulation approach used, S/O models share some of the limitations of standard simulation models. Poor physical system representation or inadequate data will cause error. One cannot properly optimize management of system processes that one cannot correctly simulate. Useful simulation/optimization modeling presupposes that aquifer parameters are appropriate and that actual boundary conditions are represented adequately within the model.

Both embedding and RM S/O models generally assume system linearity during at least some part of their processing operation. Confined aquifers are linear, unless they become unconfined. Unconfined aquifers are nonlinear, but frequently the change in transmissivity is insignificant, and they can be treated as if they were linear. Most commonly, system nonlinearity is addressed by cycling. Cycling involves (1) assuming aquifer parameters (and computing influence coefficients for RM models), (2) calculating an optimal strategy, (3) recalculating system parameters, (4) comparing assumed and newly calculated parameter values, and (5) either stopping or returning to step 2 and repeating the process (if the assumed parameter values are 
still inappropriate for the problem or if the optimal strategy is still changing with cycling). Frequentiy, three cycles are sufficient for this convergence process. Thus, although both types of models are completely applicable for confined aquifers, some adjustments must be made to accurately apply them to unconfined aquifers.

Within S/O models, plume capture is generally achieved by controlling hydraulic gradients and thus controlling advective transport. Generally, nonlinear transport equations are not included. This approach permits the modeler to retain use of the characteristics of linear systems (superposition, etc.). All of the RM model applications presented below achieve capture via gradient control.

Concerning data input, S/O models require all of the data needed by simulation models, plus information on lower and upper bounds on decision variables (pumping rate, location) and state variables (head, gradient, etc.). Although the same sort of information should be required when using an S model, the forced codification of these data as S/O model input is helpful. It causes the modeler to specify strategy acceptability criteria earlier than he/she might otherwise.

Concerning model results, an $\mathrm{S} / \mathrm{O}$ model might tell a user that the posed problem is infeasible. This means that the user has posed a problem for which all the constraints cannot be satisfied simultaneously. For example, the user might have instructed the model to cause the head near an injection cell to reach at least $100 \mathrm{~m}$ above mean sea level and simultaneously told it that the upper bound on injection in $50 \mathrm{~m}^{3} /$ day. If that injection rate is inadequate to cause the required change in head, the model will declare the problem to be infeasible. The model will be unable to determine even one pumping rate that can satisfy both conditions.

Of course, if there is more than one potential injection well, the same problem might be feasible. In that case, the model can compute an optimal pumping strategy (probably the user would have requested a strategy that minimizes the total pumping needed to achieve that head).

Fortunately, S/O model users rapidly get bcyond the stage wherein they try to develop impossible pumping strategies (force the model to achieve goals that are impossible or mutually exclusive when considering both the laws of nature and the goals of humans). Experience brings the $S / O$ modeler great ability to address common management problems.

\section{PC-BASED S/O MODELS AND SAMPLE APPLICATIONS}

\section{A. US/WELLLS ${ }^{D}$ for Systems Addressable Using Analytical Solutions}

1. Model Background

US/WELLS ${ }^{\mathrm{D}}$ (Utah State extraction/injection well system for optimal groundwater management) is a deterministic version of an RM model. It uses influence coefficients based on analytical equations for potentiometric surface response to pumping and river depletion resulting cumping from depletion. It is appropriate for systems where those analytical approaches are appropriate-presumably relatively homogeneous systems. (Of course, in the management and consulting arena, such approaches are commonly applied to heterogeneous systems, with acceptable error.)

Characteristics of US/WELLS ${ }^{D}$ are summarized in Table 2. The overview below is derived from the user's manual [15].

The objective function of the optimization module in US/WELLS is generally applicable and easily used for a variety of situations. The user can select either a linear or a quadratic form. The linear objective function is to minimize

$$
\sum_{x=1}^{2}\left[W_{E, x} \sum_{j=1}^{J} E_{j, x}+W_{l, x} \sum_{k=1}^{K} I_{k, x}\right]
$$


Table 2 Characteristics of US/WELLS ${ }^{D}$ and US/REMAX ${ }^{B}$

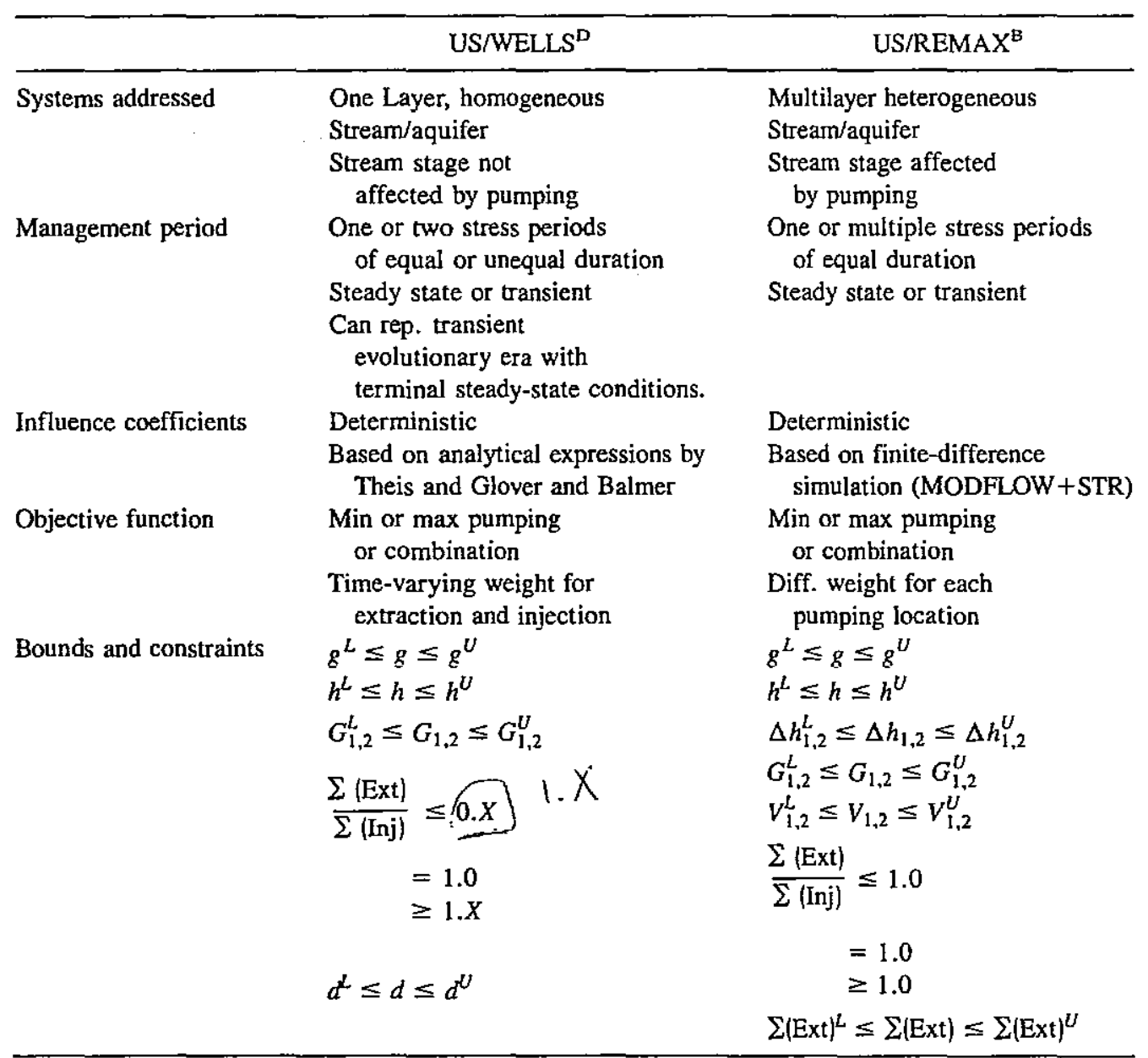

Notes: Superscripts $L$ and $U$ refer to lower and upper bounds; $g=$ extraction or injection, $\left[\mathrm{L}^{3} / \mathrm{T}\right] ; h=$ head.; $\Delta h$, $G_{1.2}, V_{1.2}=$ head-difference, gradient, and velocity, respectively, between any two locations, [L], dimensionless, or [L T ] : $\Sigma\left(\right.$ Extl, $\Sigma\left(\right.$ Inj) $=$ total extraction or injection, $\left[\mathrm{L}^{3} / \mathrm{T}\right] ; d=$ stream depletion, $\left[\mathrm{L}^{3} / \mathrm{T}\right]$.

where $W_{E, x}$ and $W_{I, x}$ are the cost coefficient or weight assigned to extraction $(E)$ or injection (I) rates in the $x_{t h}$ time period. $\left[\$ /\left(\mathrm{L}^{3} \cdot \mathrm{T}\right)\right]$ or dimensionless; $E_{j, x}$ and $J_{k_{x} x}$ are extraction $(E)$ or injection $\left(I\right.$ ) rate at well $j$ (or $k$ ) in the $x_{\text {th }}$ time period, $\left[\mathrm{L}^{3} / \mathrm{T}\right]$; and $J$ and $K$ are number of extraction $(J)$ or injection $(K)$ wells.

Potential constraints are the following.

1. Hydraulic gradient between any gradient control pair of wells at any time period must be within user-specified bounds. This can ensure that water is moving only in the desired direction. The maximum value can differ for each gradient control pair and time period. This constraint is useful, for example, when US/WELLS ${ }^{D}$ is used for groundwater contaminant plume immobilization or for any situation where hydraulic gradient control is desired.

2. Extraction or injection rate at any well must be within user-specified bounds (lower and upper limits). If the user cannot decide if a certain well should be used for extraction or injection, he can locate one of each at the same location. The model will then determine either an extraction or an injection rate, or neither, for that location. 
3. Hydraulic head at any injection, extraction, or observation well must be within userspecified lower and upper bounds. For example, a lower bound may be used to maintain adequate saturated thickness. An upper bound may be used to prevent surface flooding or to eliminate the need for pressurized injection. These lower and upper bounds can differ for different locations. The bounds are the same for both time periods.

4. Total import or export of water can be controlled to be within a user-specified range. The user can also completely prevent import or export of water or both. If no import or export of water is allowed, the total optimal extraction must equal the total optimal injection.

5. Depletion from the river must be within user-specified bounds (lower and upper limits). This is applicable only if a river exists in the considered system.

6. Constraint 3 is modified such that the probability that the actual change in head at any point in the groundwater system is not less than the change calculated by the model or is not greater than the change calculated by the model and is at least equal to the reliability level specified by the user. (This ability is found only in an alpha-test chance-constrained version of the model, US/WELLS ${ }^{S}$, which considers the stochastic nature of hydraulic conductivity. The utilized chance constraint is more accurate than previously reported formulations.)

Optionally. US/WELLS ${ }^{D}$ can use a quadratic objective function to minimize

$$
\sum_{x=1}^{2}\left[W W_{E, x} \sum_{j=1}^{J} E_{j, x} H_{j, x}+W_{E, x} \sum_{j=1}^{J} E_{j, x}+W_{l, x} \sum_{k=1}^{K} I_{k, x}\right]
$$

where $H_{j, x}$ is the dynamic lift, the difference between ground surface elevation and optimal potentiometric head resulting at extraction well $j$ at the end of the $x_{\text {th }}$ time period, [L]; and $W W_{E, x}$ is the weight assigned to the power used for extraction in the $x_{\mathrm{th}}$ time period, [\$/L.T)].

The weighting factors can be used to emphasize different criteria and different time periods. For example, assume a problem of minimizing the total extraction using the linear objective function. If the second time period is chosen to be much longer than the first time period and the weights assigned to extraction and injection in the second time period are larger than those used for the first time period, then the solution will tend to minimize steady-state extraction/injection rates, and less attention will be given to the short-term transient rates. Through the weighting factors, US/WELLS ${ }^{D}$ can also be used for maximizing pumping rates for water supply probiems.

\section{Application and Results}

Here we illustrate the use of US'WELLS ${ }^{D}$ to determine the optimal time-varying sequence of extraction and injection of water in prespecified locations needed for first immobilizing and then extracting a groundwater contaminant plume. In this example, the user specifies potential locations of extraction and injection wells around the contaminant plume (Figure 1). US/ WELLS $^{\mathrm{D}}$ then determines optimal extraction and injection rates for different time periods.

To illustrate model flexibility, four potential extraction wells and five potential injection wells are considered for placement outside the contaminant plume during the first period. In the second time period, three extraction wells are considered for placement inside the plume (to extract contaminated water) and five potential downgradient injection wells are considered. During both periods, the resulting hydraulic gradients (between 10 pairs of head observation locations) must be toward the center of the plume. Alternatively, the user could choose to minimize the pumping needed to capture the plume using only internal extraction wells in one or both periods. 


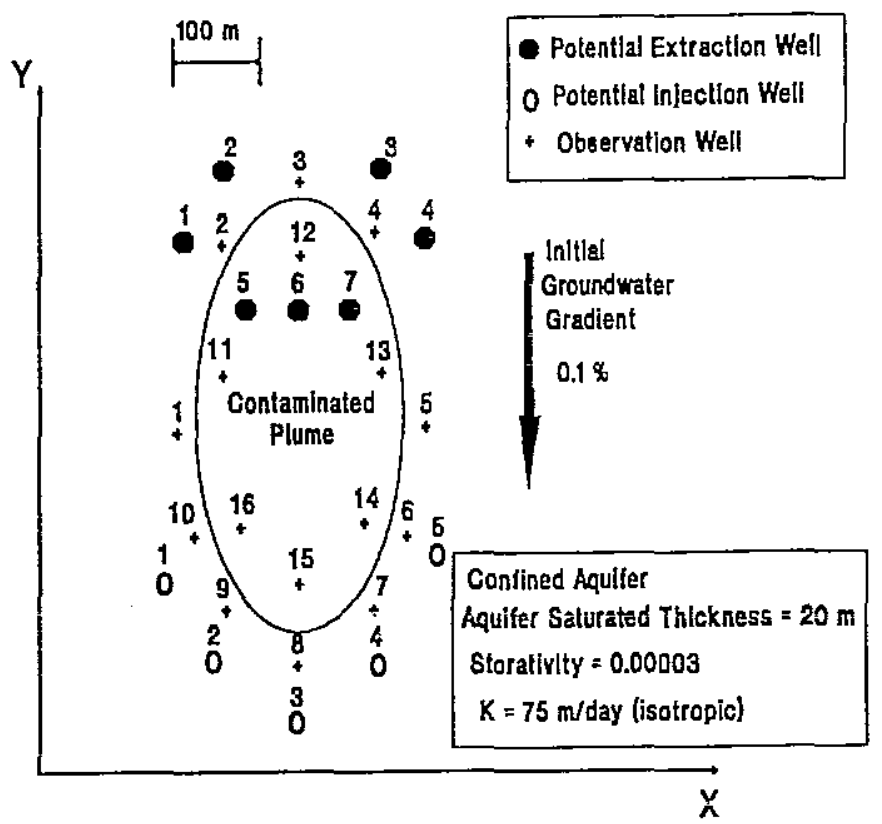

Figure 1 Hypothetical study area for Example A, addressable with US/WELLS ${ }^{D}$.

Here, the quadratic objective function is used and employs greater weights for the second time period than the first period. This supports the fact that the second period is much longer than the first. In addition, neither export nor import of water is allowed-total injection must equal total extraction in each period. All the above considerations are incorporated within the model via the input data [15]. The user also specifies lower and upper bounds on head and pumping rates.

Figure 2 shows US/WELLS ${ }^{D}$ output, in meters and $\mathrm{m}^{3} /$ day. This contains, in addition to the input bounds (L. Bound and U. Bound), the optimal values of the decision variables (pumping), state variables (head and gradient), and marginal values.

The marginal is defined as the value by which the objective function will change if a tightly bounded variable changes one unit. If a variable's optimal value is not equal to either its lower or upper bound, its marginal will be zero. That is, the marginal will be nonzero only if the optimal value of the variable equals one of its bounds. In this case, the marginal shows the improvement of the value of the objective function resulting from relaxing this bound by one unit. Marginals are valid only as long as no other variable also changes in value. Thus they might be valid for only a small range of change in the bound.

To illustrate, the output file (Figure 2) shows that the marginal of the optimal injection rate in the first time period at injection well 3 is -45.3 . The objective function value was $334,668.1$. If the upper bound on injection in the first time period is relaxed by one unit at the mentioned well (that is, the new upper bound is 901 instead of 900), one would expect the value of the objective function to change by about -45.3 to $334,622.8$. If this change is actually made and the model is rerun, the resulting change in objective function value is -45.4 .

Marginals are useful in determining how to refine an optimal strategy. They help one to decide which bounds or constraints should be looked at more closely and perhaps relaxed. They also indicate the trade-off between that bound and objective achievement. They show how much one is giving up in terms of objective attainment to satisfy that restriction. 
JOBNAME: No Job Name PAGE: 8 SESS: 18 OUTPUT: Tue Aug 24 01:09:35 1993

/xycomp/ - main - /booksm - $z /$ marcel/2554engin/ch 29

MODEL STATUS : OPTIMAL SOLUTION FOUND VALUE OF OBJECTIVE FUNCTION 334668.1

OPTIMAL EXTRACTION RATES

$\begin{array}{ccrrc}\text { Well No } & \begin{array}{c}\text { FIRST TIME } \\ \text { L.Bound }\end{array} & \begin{array}{l}\text { PERIOD } \\ \text { Optimal }\end{array} & \text { U. Bound } & \text { Marginal } \\ 1 & 0.00 & 745.42 & 900.00 & 0.000 \\ 2 & 0.00 & 447.60 & 900.00 & 0.000 \\ 3 & 0.00 & 448.71 & 900.00 & 0.000 \\ 4 & 0.00 & 747.86 & 900.00 & 0.000 \\ 5 & 0.00 & 0.00 & 0.00 & 0.000 \\ 6 & 0.00 & 0.00 & 0.00 & 0.000 \\ 7 & 0.00 & 0.00 & 0.00 & 0.000\end{array}$

\begin{tabular}{|c|c|c|c|c|}
\hline $\begin{array}{r}\text { Well No } \\
1 \\
2 \\
3 \\
4 \\
5 \\
6 \\
7\end{array}$ & $\begin{array}{l}\text { SECOND TIME } \\
\text { L. Bound } \\
0.00 \\
0.00 \\
0.00 \\
0.00 \\
0.00 \\
0.00 \\
0.00\end{array}$ & $\begin{array}{r}\text { PERIOD } \\
\text { Optimal } \\
0.00 \\
0.00 \\
0.00 \\
0.00 \\
426.53 \\
883.77 \\
428.90\end{array}$ & $\begin{array}{r}\text { U. Bound } \\
0.00 \\
0.00 \\
0.00 \\
0.00 \\
900.00 \\
900.00 \\
900.00\end{array}$ & $\begin{array}{l}\text { Marginat } \\
81.955 \\
81.627 \\
81.605 \\
81.913 \\
0.000 \\
0.000 \\
0.000\end{array}$ \\
\hline
\end{tabular}

OPTIMAL INJECTION RATES

$\begin{array}{ccccc}\text { FIRST TIME } & \text { PERIOD } & & \\ \text { Hell No } & \text { L.Bound } & \text { Optimat } & \text { U.Bound } & \text { Marginal } \\ 1 & 0.00 & 211.66 & 900.00 & 0.000 \\ 2 & 0.00 & 328.89 & 900.00 & 0.000 \\ 3 & 0.00 & 900.00 & 900.00 & -45.342<===\text { explained in text } \\ 4 & 0.00 & 900.00 & 900.00 & 0.000 \\ 5 & 0.00 & 49.04 & 900.00 & 0.000\end{array}$

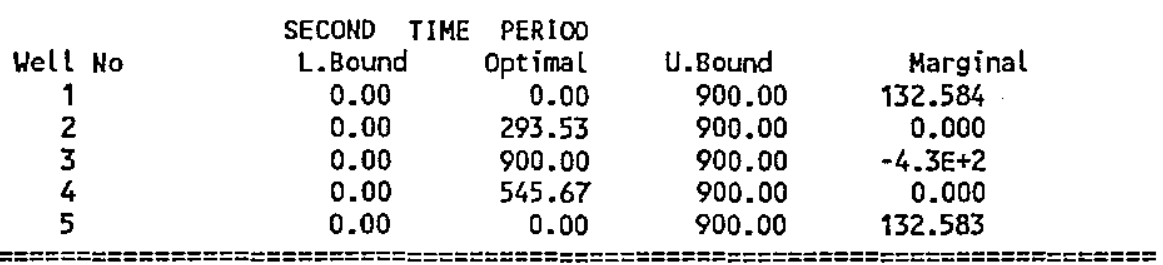

OPTIMAL HEADS AT OBSERVATION WELLS

\begin{tabular}{|c|c|c|c|c|}
\hline & FIRST TIME & PERIOD & & \\
\hline Well No & L. Bound & Optimal & U.Bound & Harginal \\
\hline 1 & 30.00 & 35.69 & 40.00 & 0.000 \\
\hline 2 & 30.00 & 35.54 & 40.00 & 0.000 \\
\hline 3 & 30.00 & 35.60 & 40.00 & 0.000 \\
\hline 4 & 30.00 & 35.55 & 40.00 & 0.000 \\
\hline 5 & 30.00 & 35.70 & 40.00 & 0.000 \\
\hline 6 & 30.00 & 35.79 & 40.00 & 0.000 \\
\hline 7 & 30.00 & 35.92 & 40.00 & 0.000 \\
\hline 8 & 30.00 & 35.88 & 40.00 & 0.000 \\
\hline 9 & 30.00 & 35.84 & 40.00 & 0.000 \\
\hline 10 & 30.00 & 35.77 & 40.00 & 0.000 \\
\hline 11 & 30.00 & 35.65 & 40.00 & 0.000 \\
\hline 12 & 30.00 & 35.60 & 40.00 & 0.000 \\
\hline 13 & 30.00 & 35.65 & 40.00 & 0.000 \\
\hline 14 & 30.00 & 35.79 & 40.00 & 0.000 \\
\hline 15 & 30.00 & 35.88 & 40.00 & 0.000 \\
\hline 16 & 30.00 & 35.77 & 40.00 & 0.000 \\
\hline
\end{tabular}

Figure 2 US/WELLS ${ }^{D}$ output file for Example A. 
JOBNAME: No Job Name PAGE: 9 SESS: 18 OUTPUT: Tue Aug 24 01:09:35 1993

/xycomp/-main - /booksm $-z /$ marcel/2554engin/ch29

PC Software for Optimizing Plume Capture

\begin{tabular}{|c|c|c|c|c|}
\hline & SECOND TIME & PER IOD & & \\
\hline Well No & L.Bound & Opt imal & U. Bound & Marginal \\
\hline 1 & 30.00 & 35.62 & 40.00 & 0.000 \\
\hline 2 & 30.00 & 35.62 & 40.00 & 0.000 \\
\hline 3 & 30.00 & 35.68 & 40.00 & 0.000 \\
\hline 4 & 30.00 & 35.62 & 40.00 & 0.000 \\
\hline 5 & 30.00 & 35.63 & 40.00 & 0.000 \\
\hline 6 & 30.00 & 35.66 & 40.00 & 0.000 \\
\hline 7 & 30.00 & 35.75 & 40.00 & 0.000 \\
\hline$B$ & 30.00 & 35.74 & 40.00 & 0.000 \\
\hline 9 & 30.00 & 35.71 & 40.00 & 0.000 \\
\hline 10 & 30.00 & 35.64 & 40.00 & 0.000 \\
\hline 11 & 30.00 & 35.56 & 40.00 & 0.000 \\
\hline 12 & 30.00 & 35.54 & 40.00 & 0.000 \\
\hline 13 & 30.00 & 35.56 & 40.00 & 0.000 \\
\hline 14 & 30.00 & 35.66 & 40.00 & 0.000 \\
\hline 15 & 30.00 & 35.74 & 40.00 & 0.000 \\
\hline 16 & 30.00 & 35.64 & 40.00 & 0.000 \\
\hline
\end{tabular}

OPTIMAL HEADS AT EXTRACTION WELLS

FIRST TIME PERIOD

$\begin{array}{cllll}\text { Hell No } & \text { L.Bound } & \text { Optimal } & \text { U.Bound } & \text { Marginal } \\ 1 & 30.00 & 35.09 & 40.00 & 0.000 \\ 2 & 30.00 & 35.29 & 40.00 & 0.000 \\ 3 & 30.00 & 35.29 & 40.00 & 0.000 \\ 4 & 30.00 & 35.09 & 40.00 & 0.000 \\ 5 & 30.00 & 35.61 & 40.00 & 0.000 \\ 6 & 30.00 & 35.62 & 40.00 & 0.000 \\ 7 & 30.00 & 35.61 & 40.00 & 0.000\end{array}$

SECOND TIME PERIDO

$\begin{array}{cllll}\text { Hell No } & \text { L.Bound } & \text { Optimat } & \text { U.Bound } & \text { Marginal } \\ 1 & 30.00 & 35.69 & 40.00 & 0.000 \\ 2 & 30.00 & 35.72 & 40.00 & 0.000 \\ 3 & 30.00 & 35.73 & 40.00 & 0.000 \\ 4 & 30.00 & 35.70 & 40.00 & 0.000 \\ 5 & 30.00 & 35.24 & 40.00 & 0.000 \\ 6 & 30.00 & 34.90 & 40.00 & 0.000 \\ 7 & 30.00 & 35.25 & 40.00 & 0.000\end{array}$

OPTIMAL HEADS AT IHJECTION HELLS

FIRST TIHE PERIOO

$\begin{array}{cclll}\text { Hell No } & \text { L.Bound } & \text { Optimal } & \text { U.Bound } & \text { Marginal } \\ 1 & 30.00 & 35.90 & 40.00 & 0.000 \\ 2 & 30.00 & 36.03 & 40.00 & 0.000 \\ 3 & 30.00 & 36.46 & 40.00 & 0.000 \\ 4 & 30.00 & 36.47 & 40.00 & 0.000 \\ 5 & 30.00 & 35.83 & 40.00 & 0.000 \\ & & & & \\ & \text { SECOND IIME } & \text { PERIOD } & & \\ \text { Hell No } & & & & \\ 1 & \text { L.80und } & \text { Optimal } & \text { U.Bound } & \text { Marginal } \\ 2 & 30.00 & 35.65 & 40.00 & 0.000 \\ 3 & 30.00 & 35.88 & 40.00 & 0.000 \\ 4 & 30.00 & 36.33 & 40.00 & 0.000 \\ 5 & 30.00 & 36.08 & 40.00 & 0.000 \\ & 30.00 & 35.67 & 40.00 & 0.000\end{array}$

Figure 2 Continued. 
OPTIMAL HYDRAULIC GRADIENTS

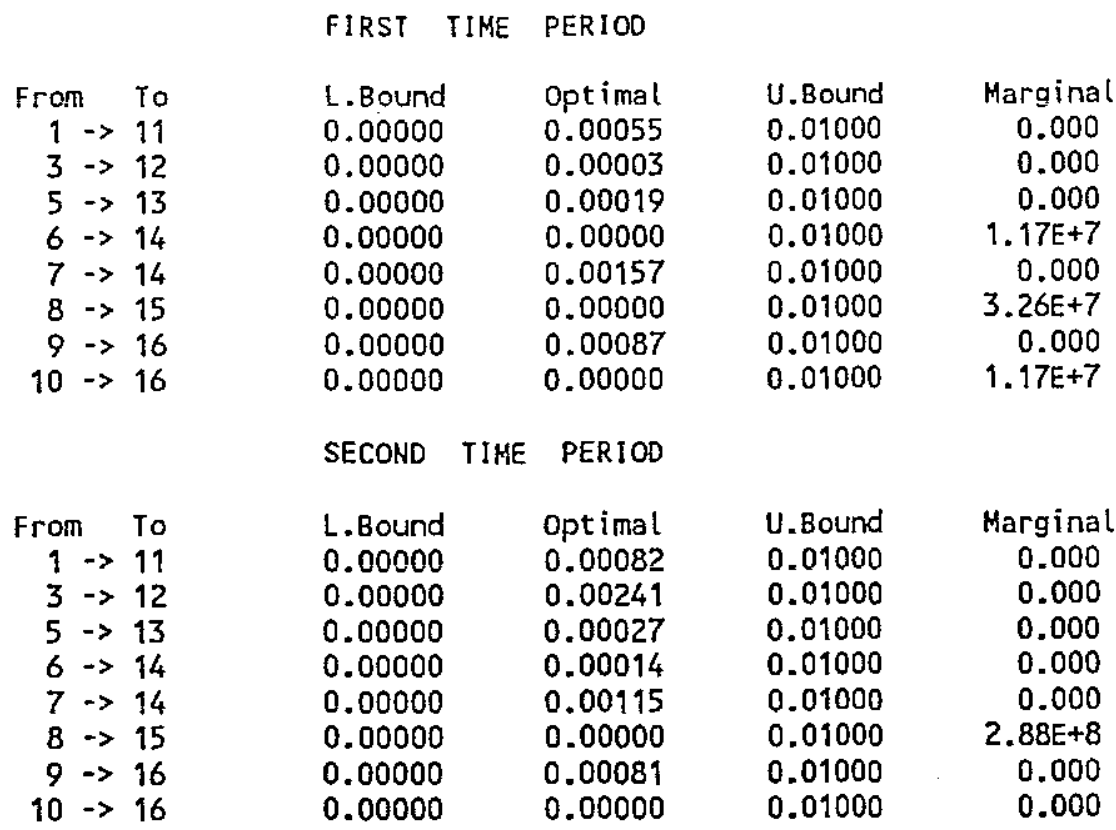

Figure 2 Concluded.

\section{B. US/REMAX ${ }^{B}$ for Heterogeneous Multilayer Systems}

1. Model Background

For optimizing management of complex heterogeneous systems, one would rather use US/

$B$ REMAX ${ }^{\mathrm{D}}[16]$ than US/WELLS ${ }^{\mathrm{D}}$. This is the basic version of the Utah State response matrix model. To develop influence coefficients, it uses code modified from MODFLOW, a modular finite-difference groundwater flow simulation model [4], and STR, a related stream routing module [17]. The physical system data needed by US/REMAX ${ }^{\mathrm{D}}$ can be input in the same format as is used by MODFLOW and STR. Internally, US/REMAX ${ }^{\mathrm{B}}$ also uses a portion of PLUMAN, a decision support system for optimal groundwater contaminant plume management [18], and other code.

The optimization model formulation capabilities are similar to those of US/WELLS ${ }^{\mathrm{D}}$ (Table 2). For steady state, the generic objective is to minimize

$$
\sum_{j=1}^{J} W_{j} E_{j}+\sum_{k=1}^{K} W_{k} I_{k}
$$

where $W_{j}$ is the weight assigned to pumping in cell $j$, dimensionless or $\left[\$ \cdot T / L^{3}\right] . U S / R^{2}$ MAX ${ }^{B}$ can employ constraints $1-3$ of US/WELLS ${ }^{D}$ for multiple layers. Similar to the US/WELLS ${ }^{D}$ constraint 4, US/REMAX ${ }^{B}$ can force total extraction to exceed, equal, or be less than total injection. Again, via the sign on the weighting coefficients, one can perform maximization. One can also achieve multiobjective optimization by the weighting method. Whereas in US/ WELLS ${ }^{\mathrm{D}}$ the same weight must be applied to all extraction wells in a time step (and a different weight can be used for injection wells, but the same must be applied to all such wells in a particular time step), in US/REMAX ${ }^{B}$ each well can employ a different weight. 
2. Application and Results

Introduction. For illustration, we discuss addressing a contaminant plume in a representative study area. First, the study area is described and the results of continuing current management are predicted, using MODFLOW+STR for flow simulation and MOC [19] for transport simulation. Then an approach to developing an optimal strategy is discussed, the S/O model is applied, and an optimal strategy is computed. Next, the system response to implementing the optimal strategy is verified using MODFLOW +STR and MOC. Finally, slight variations in the management goal or situation are assumed and new optimal strategies are developed. Computed optimal strategies are compared. Suguino [20] first addressed this study area using PLUMAN. Some of the discussion below follows his development.

Study Area Description and Situation. The area (Figure 3) measures about $4.3 \mathrm{~km}$ by $4.3 \mathrm{~km}$. It is bounded on the north by a large saltwater body; on the south, east, and northwest by impermeable material; and on the west by a lake. A river transects the area from south to north. Aquifer parameters of this example study area were obtained from ranges reported by Todd [21].

For the unconfined upper layer (layer 1 ), parameters are as follows.

Hydraulic conductivity:

1st zone: $45 \mathrm{~m} /$ day (coarse sand) from lake to contaminant spill area (columns $1-36$ and 57-58)

2nd zone: 30 miday (medium sand) in irrigated area (columns 51-56)

3rd zone: $450 \mathrm{~m} /$ day (fine gravel) in contaminant spill area (columns $37-50$ ).

Specific yield:

1st zone: $\quad 0.27$ (coarse sand)

2nd zone: 0.28 (medium sand)

3rd zone: 0.25 (fine gravel)

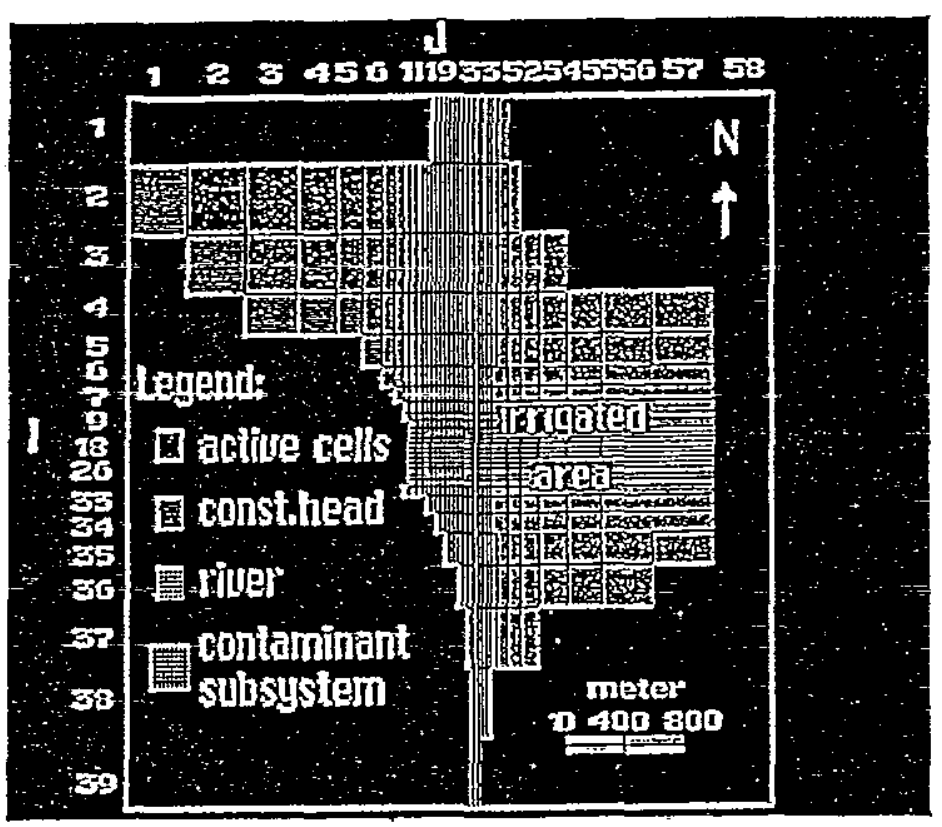

Figure 3 Finite-difference grid for the area addressable with US/REMAX ${ }^{B}$. 
Recharge by deep percolation and/or irrigation:

$1.167 \times 10^{-8} \mathrm{~m} / \mathrm{sec}$ in nonirrigated area

$1.928 \times 10^{-8} \mathrm{~m} / \mathrm{sec}$ in irrigated area

In the confined lower layer (layer 2):

Transmissivity: $\quad 0.1564 \mathrm{~m}^{2} / \mathrm{sec}$

Saturated thickness: $30.0 \mathrm{~m}$

Storage coefficient: $\quad 0.0001$

Finite-difference models are to be used in this study. This requires system discretization. The resulting block-centered cell grid (Figure 3 ) has 58 columns and 39 rows. Cell side lengths range from 3 to $400 \mathrm{~m}$. Because MOC will be used for transport simulation near the plume, cells of uniform size are specified for that region. The resulting 17 row by 20 column region (subsystem) near the plume has square cells of $15.2 \mathrm{~m}(50 \mathrm{ft}$ ) side length.

A conservative (nonreactive) contaminant is assumed to be spilled in the top aquifer layer (layer 1 ) of cell $(22,18)$ or $\left(11_{s}, 3_{s}\right)$. (The subscript "s" after a cell row or column index indicates that the cell is in the subsystem.) This cell is treated as a continuous source during the management period.

Initially, pumping for water supply occurs in two cells between the plume and the river. One well is in layer 1 of $(23,15)$ or $\left(12_{s}, 15_{s}\right)$. The other well is in layer 2 of $(18,18)$ or $\left(7_{s}\right.$, $\mathrm{i} 8_{\mathrm{s}}$ ). There is immediate concern about the potentiai for contamination reaching the suppiy well in layer 1.

Nonoptimal System Response Determination (Step 1). Before one attempts to develop an optimal strategy, one usually demonstrates the need for such a strategy. This requires predicting system response if no optimal strategy is implemented. Frequently, simulation models are used for this action. Here, MODFLOW+STR computes the potentiometric surface that will result from assumed steady-state conditions (Figure 4).

Because of the gradient, the contaminant will tend to migrate toward the supply wells. MOC is used to quantify the migration resulting in the subsystem from the steady flow. Figure 5 shows the $210 \mathrm{ppb}$ contour expected to result 60 days after contamination begins. Furthermore, concentration in the cell containing the drinking well $\left(12_{\mathrm{s}}, 15_{\mathrm{s}}\right)$ reaches $317 \mathrm{ppb} 8$ months after the spill. We assume that this concentration level exceeds the health advisory for human consumption and that developing a plume capture strategy is desirable.

Management Goals Specification and S/O Model Formulation for Scenario 1 (Step 2). The assumed goal is to minimize the steady pumping (extraction and injection) needed to capture the plume. Plume capture will presumably be achieved when hydraulic gradients, just outside the plume boundary, all point toward the plume interior. We also want the head at extraction wells not to drop too far (to avoid reducing saturated thickness by more than about 10\%) or the head at injection wells not to rise to the ground surface. These criteria identify the example problem termed Scenario 1 .

The S/O model formulation for this scenario is shown below. The model computes the pumping strategy that minimizes the value of the objective function, subject to the stated constraints and bounds. Locations of potential injection and extraction wells to be considered by the model are shown in Figure. 5. Figure 6 identifies head difference (gradient) control cell pairs and shows the direction that will be imposed on the hydraulic gradient by any computed optimal strategy. These are placed to enclose the plume projected to exist by day 60 . A modeler can select potential well locations on the basis of practical experience. For example, the closer the injection wells are to the head gradient control locations, the less pumping is needed to 


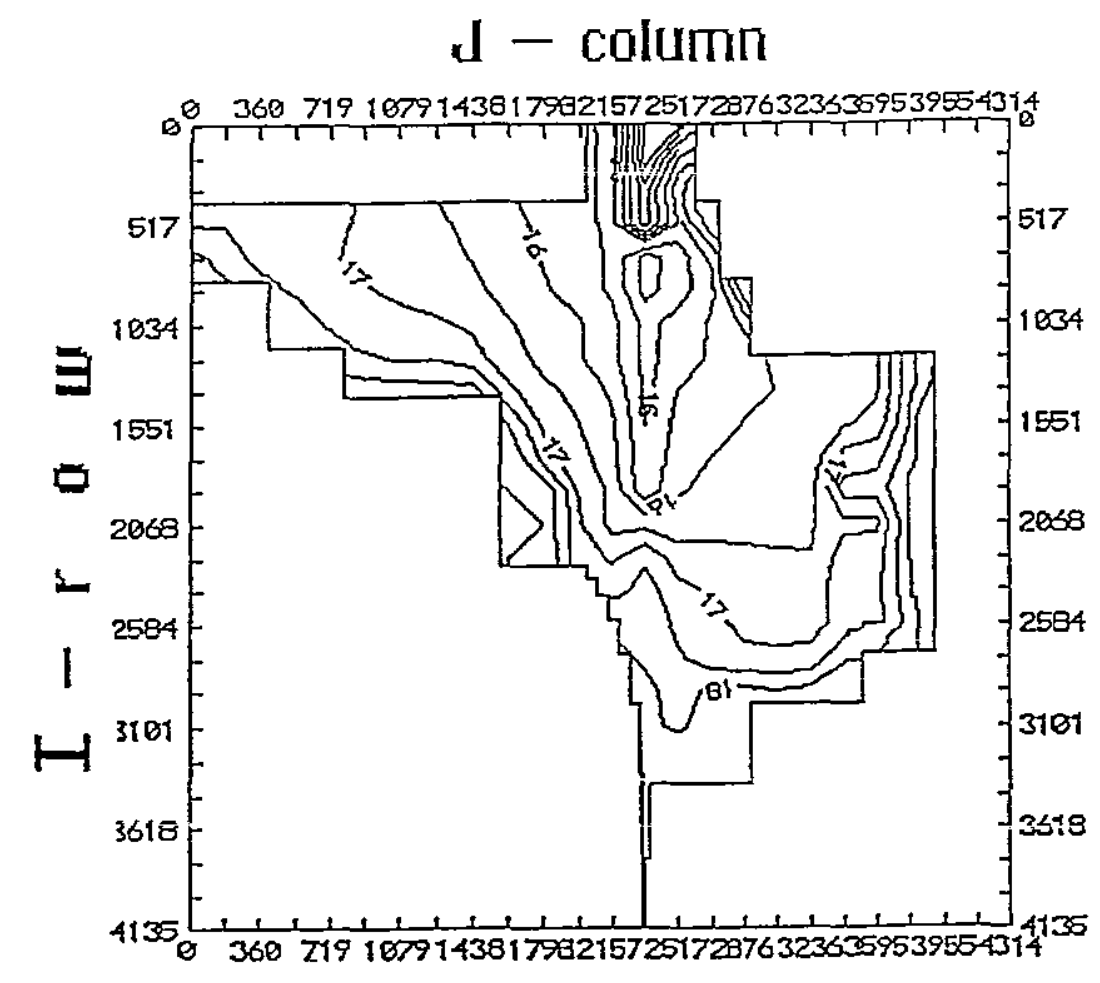

Figure 4 Nonoptimal (unmanaged) steady-state potentiometric surface contour map for the study area of Scenario 1 (meters above MSL).

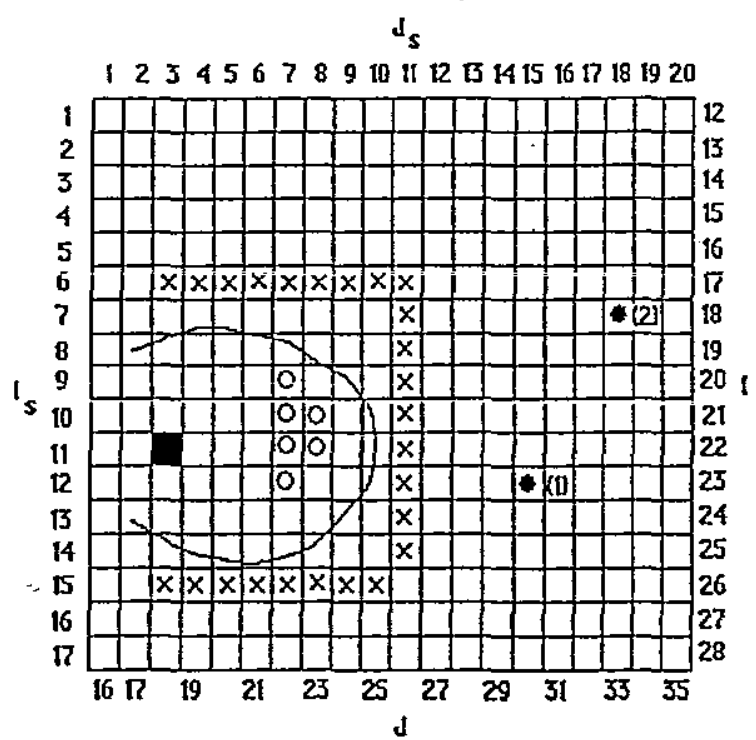

Legend:

0 unmanaged well

(1) tayer 1

(2) layer 2

冈 potential managed injection well

[0] potential managed

estraction well

a contamintiant solite

元 $210 \mathrm{ppb}$ concentration

contour

meter

o is 3045

Figure 5 Subsystem discretization, potential well locations for Scenario 1, and 210 ppin contour, 60 days after contamination begins. 


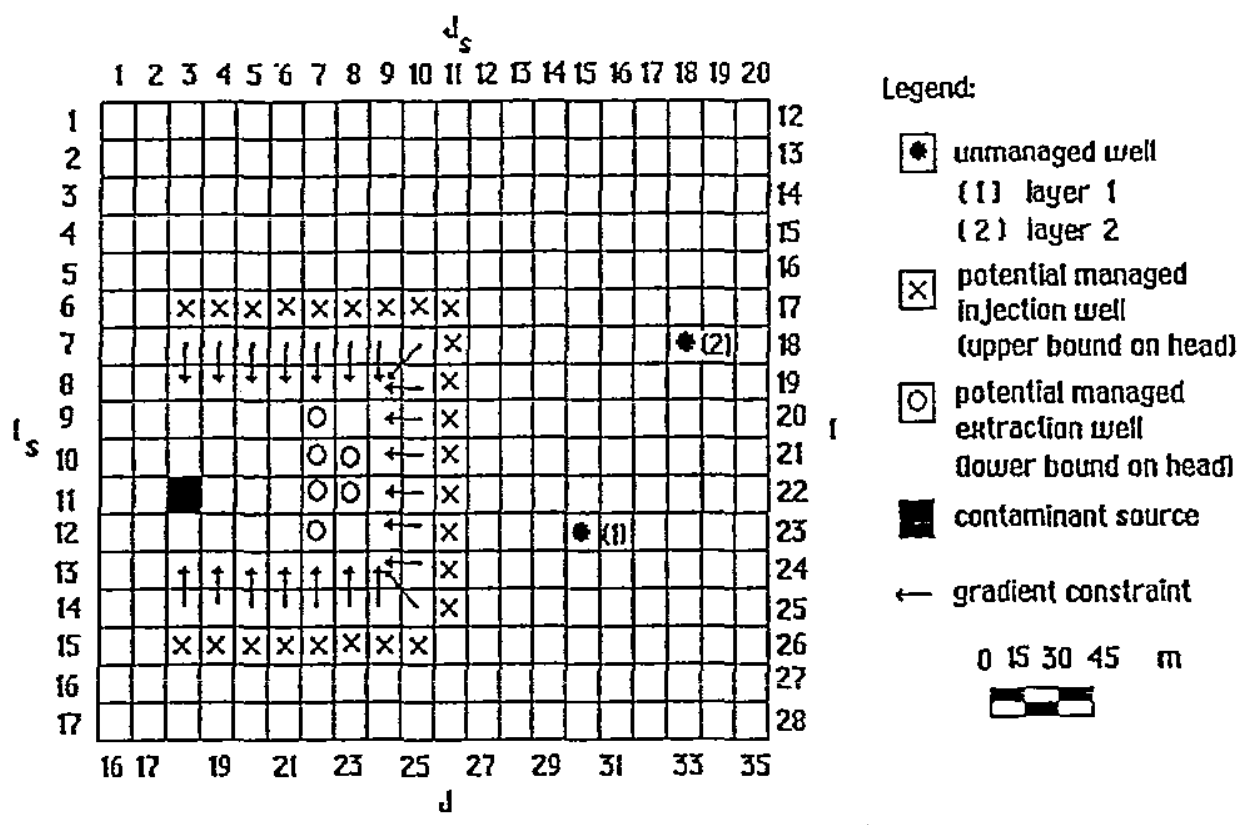

Figure 6 Head-difference constraint locations applied within the S/O model in Scenario 1.

satisfy the head-difference constraint. Thus, the modeler might want the model to consider pumping sites near the location where heads need most to be affected.

The model objective is to minimize the value of Equation (3), using weights of 1, subject to

$$
\begin{array}{ll}
G_{\bar{o}} \geq 0.01, & \text { for } \bar{o}=1, \ldots, 22 \\
h_{\hat{e}} \geq 15.0, & \text { for } \hat{e}=1, \ldots, 6 \\
h_{\hat{e}} \leq 25.0, & \text { for } \hat{e}=1, \ldots, 25
\end{array}
$$

where $G_{\tilde{b}}$ is the difference in head between a pair of cells, the first located farther from the plume. A positive value denotes a higher head farther from the plume, [L]; $h_{\hat{c}}$ is the hydraulic head just outside the casing of pumping well $\hat{e}$ located in the center of a pumping cell, $[\mathrm{L}] ; \bar{o}$ is the index denoting pair of cells head-difference (gradient) control pair; and $\hat{e}$ is the index denoting pumping well at the center of cell $j$ or $k$. Here $j=6$ and $k=25$.

Note that identifying the location of potential extraction and injection wells for the model (Figure 5) does not mean that the model will choose to pump at those locations. Via the optimization process, the model might choose to pump at only a few of the potential sites. The computed strategy will require less total pumping than any other strategy possible for the specified potential well locations and imposed bounds and constraints. Furthermore, since this is a steady-state problem, steady-state system response to implementing the strategy computed by the model will satisfy all those bounds and constraints. This is verified in the next step.

Optimal Strategy Computation and Verification for Scenario l (Step 3). The optimal strategy computed for Scenario 1 is shown in Table 3. Because the model is minimizing pumping only for plume containment in layer 1 , no extraction is shown for layer 2 . The original unmanaged pumping does continue from original supply wells in both layers (Figure 3) but is not included in Table 3 because the model is not optimizing that pumping. 
Table 3 Pumping Results for the Sample Scenarios

\begin{tabular}{|c|c|c|c|c|c|}
\hline \multirow[b]{2}{*}{ Scenario } & \multirow[b]{2}{*}{ Constraints } & \multicolumn{2}{|c|}{$g($ extr $)$} & \multirow{2}{*}{$\begin{array}{c}b(\mathrm{inj} .) \\
\left(\mathrm{m}^{3} / \mathrm{sec}\right)\end{array}$} & \multirow{2}{*}{$\begin{array}{c}(g+b) \text { total } \\
(\mathrm{gpm})\end{array}$} \\
\hline & & 1st Layer & 2nd Layer & & \\
\hline 1 & $\begin{array}{l}\text { Gradient constraint on } \\
\text { heads located on the same } \\
\text { layer, head constraint on } \\
\text { injection and extraction well. }\end{array}$ & $\begin{array}{r}0.01338 \\
(212.05)\end{array}$ & - & $\begin{array}{l}0.02020 \\
(320.13)\end{array}$ & $\begin{array}{l}0.03358 \\
(532.18)\end{array}$ \\
\hline 2 & $\begin{array}{l}\text { Added pumping constraint: } \\
\text { total sum of extraction }=\text { total } \\
\text { sum of injection. }\end{array}$ & $\begin{array}{c}0.01702 \\
(269.74)\end{array}$ & - & $\begin{array}{l}0.01702 \\
(269.74)\end{array}$ & $\begin{array}{l}0.03404 \\
(539.48)\end{array}$ \\
\hline 3 & $\begin{array}{l}\text { Gradient constraint on heads } \\
\text { located on the same and on } \\
\text { different layers, head constraint } \\
\text { on injection and extraction wells. }\end{array}$ & $\begin{array}{l}0.00300 \\
(47.54)\end{array}$ & $\begin{array}{l}0.00329 \\
(52.14)\end{array}$ & $\begin{array}{l}0.03786 \\
(600.03)\end{array}$ & $\begin{array}{l}0.04415 \\
(699.69)\end{array}$ \\
\hline
\end{tabular}

Figure 7 shows the locations of wells that will pump, according to the optimal strategy. It also shows the head-difference constraints [Equation (4)] that will be tight. Tight constraints are those that are satisfied exactly. The other gradient constraints are also satisfied, but the model had no difficulty in doing so. These latter head-difference constraints are "loose" (there is more than $0.01 \mathrm{~m}$ difference between the heads at the two cells coupled by an arrow in Figure 6 but not shown at all in Figure 7). No heads are against their bounds. Therefore neither Equation (5) nor (6) is tight.

It is appropriate to verify that the computed strategy accomplished its goal of plume capture. MODFLOW+STR can be used to demonstrate how quickly the optimal steady pumping

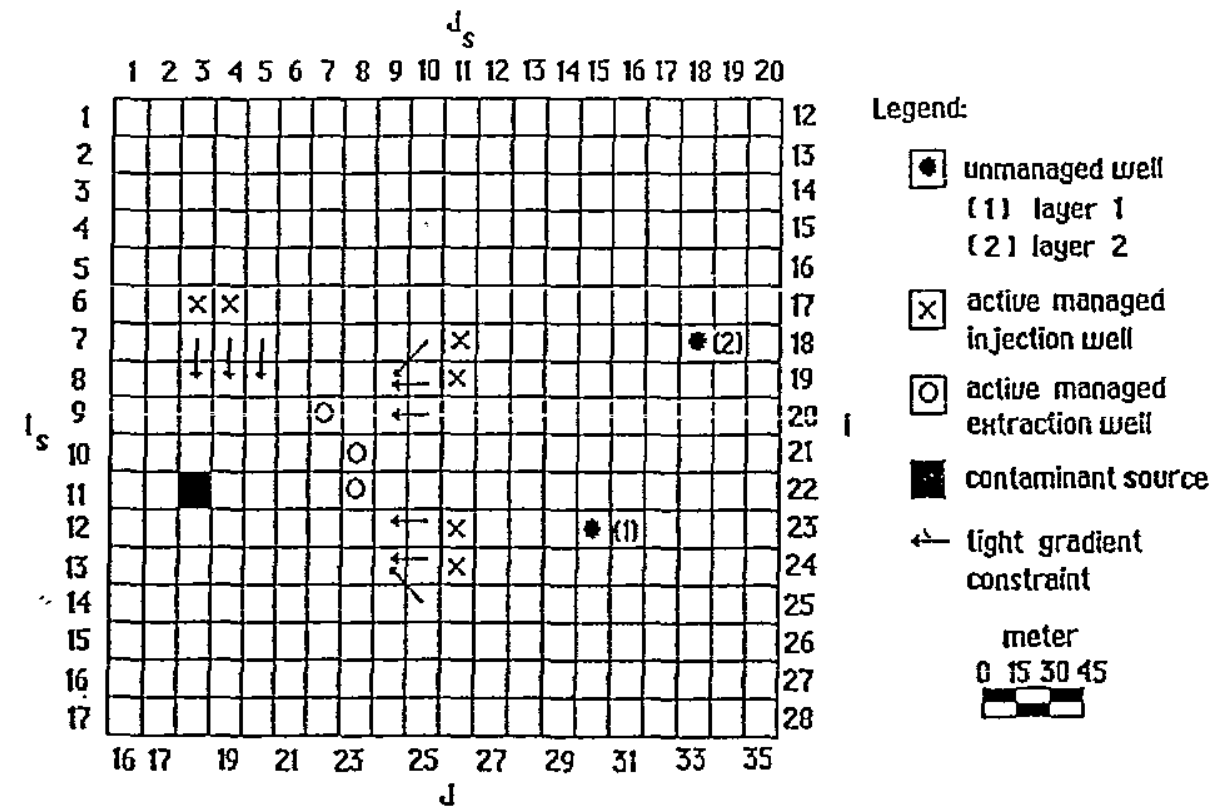

Figure 7 Location of optimal pumping wells and tight head-difference (gradient) constraints for Scenario 1 . 
strategy will cause the desired gradients to occur. Transient simulation demonstrated that the gradient constraints would be satisfied 30 days after implementing the optimal pumping strategy (Figure 8). Figures 9 and 10 show the ultimate steady-state surface resulting from strategy implementation. Clearly, a groundwater divide has been formed between the plume and the supply well.

MOC is used to predict the pollutant transport that would result from strategy implementation. No contaminant moved past the injection wells.

Theoretical verification of the optimality of the computed strategy is beyond the scope of this document. However, many texts on operations research and linear programming assure the optimality of solutions to models having a linear objective function and constraints.

\section{Alternative Scenarios.}

Scenario 2. This scenario differs from the previous in the addition of a constraint forcing total injection to equal total extraction around the plume. Again, pumping from the two supply wells is not included in the total.

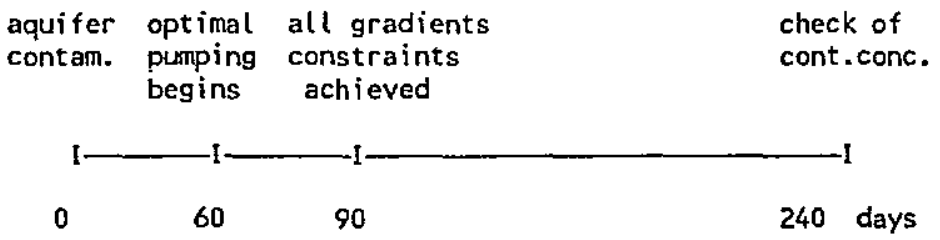

Figure 8 Time scale of Scenario 1.

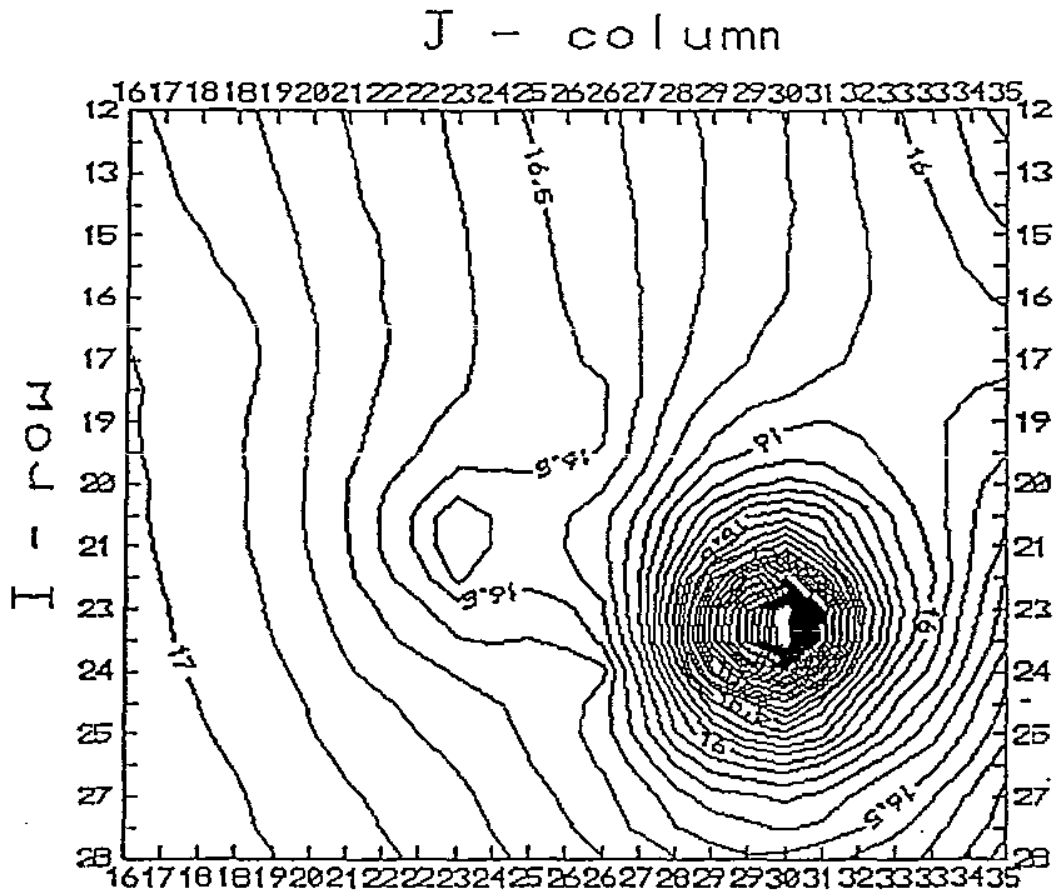

Figure 9 Subsystem potentiometric surface resulting from implementing the optimal pumping strategy for Scenario 1 (meters above MSL). 
JOBNAME: No Job Name PAGE: 17 SESS: 19 OUTPUT: Tue Aug 24 01:24:12 1993

/xycomp/ - main -/booksm - z/marcel/2554engin/ch29

PC Software for Optimizing Plume Capture

\begin{tabular}{|crrrrr|}
\hline Well & Ips & gpm & Well & lps & gpm \\
$t$ & 1.36 & 21.56 & 6 & -3.09 & -49.02 \\
2 & 0.62 & 9.89 & 7 & 5.02 & 79.58 \\
3 & -0.60 & -9.49 & 8 & 4.46 & 70.67 \\
4 & -9.69 & -155.55 & 9 & 7.88 & 124.96 \\
5 & 0.85 & 15.46 & 10 & $-100.00-158482$ \\
\hline
\end{tabular}

$(+)$ recharge (-) withdrowal

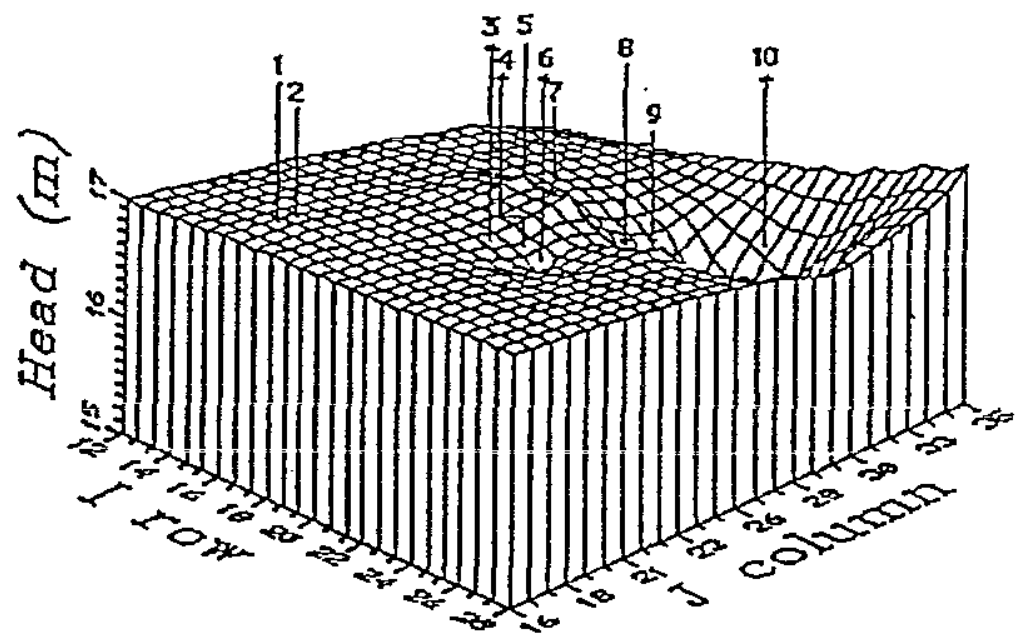

Figure 10 Subsystem potentiometric surface resulting after 6 months of optimal pumping for Scenario 1 (meters above MSL).

Results in Table 3 show an increase in extraction and a decrease in injection. Total pumping needed for plume containment increased slightly (1.4\%). This illustrates the phenomenon-increasing the number or restrictiveness of constraints does not improve the value of the objective function.

Although total pumping increased, one less extraction well is used in this strategy than in the previous (Table 4). The same number of gradient constraints are tight, but the locations of the tight gradient constraints differ slightly.

Scenario 3. This scenario demonstrates what might happen if involved managers have conflicting goals. It differs slightly from Scenario 1. In addition to controlling the plume, the agency wishes to extract more from layer 2 for water supply. Three new potential extraction wells are located in cells $(19,25),(20,25)$, and $(21,25)$, as if along a nearby road. Pumping is not permitted to change at the two initial supply wells.

Table 4 Numbers of Managed Wells that Will Pump Under the Optimal Strategies for the Tested Scenarios

\begin{tabular}{lccccc}
\hline \multirow{2}{*}{ Scenario } & \multicolumn{2}{c}{$g($ extr. $)$} & & \\
\cline { 2 - 5 } & 1st Layer & 2nd Layer & $b($ inj. $)$ & $(g+b)$ total \\
\hline 1 & 3 & - & 6 & 9 \\
2 & 2 & - & 6 & 8 \\
3 & 4 & 3 & 14 & 21 \\
\hline
\end{tabular}


As a result, the objective function is altered to maximize new extraction from layer 2 while still minimizing the pumping in layer 1 needed to capture the plume. This is achieved by assigning a negative sign to extraction from the supply wells, and minimizing:

$$
\sum_{j=1}^{J}\left(E_{j}\right)_{1 \text { st layer }}-\left(E_{j}\right)_{2 \text { nd layer }}+\sum_{k=1}^{K}\left(I_{k}\right)_{1 \text { st layer }}
$$

Since minimizing a negative number is the same as maximizing a positive number, minimizing negative extraction in layer 2 means maximizing that extraction.

Also added are new constraints imposed on vertical flow in cells $(21,21)$ and $(22,21)$. There, the head in the lower layer is forced to exceed that in the upper layer by $0.01 \mathrm{~m}$, preventing the downward migration of contaminant.

Figure 11 shows the resulting optimal injection and extraction well locations and tight gradient constraints. The optimal pumping strategy includes seven extraction wells and 14 injection wells. Although extraction of polluted water decreases, injection increases with respect to Scenario 1 (Table 3). Extraction of water for public supply increases by $31 \%$ above the unmanaged rate.

Although the gradient constraints are all satisfied by the optimal strategy, subsequent simulation demonstrated that the vertical gradient is reversed in some piume-containing celis in which the gradient was unconstrained. This illustrates that one must be careful in placing head or gradient control in appropriate locations. In practice, another optimization would be performed, using additional vertical head-difference or gradient constraints.

Processing Considerations. It is useful to consider the resources required to address optimization problems. First, the total computer time needed to solve an optimization problem is of

\section{$d_{s}$}

123456789101112151415661218920

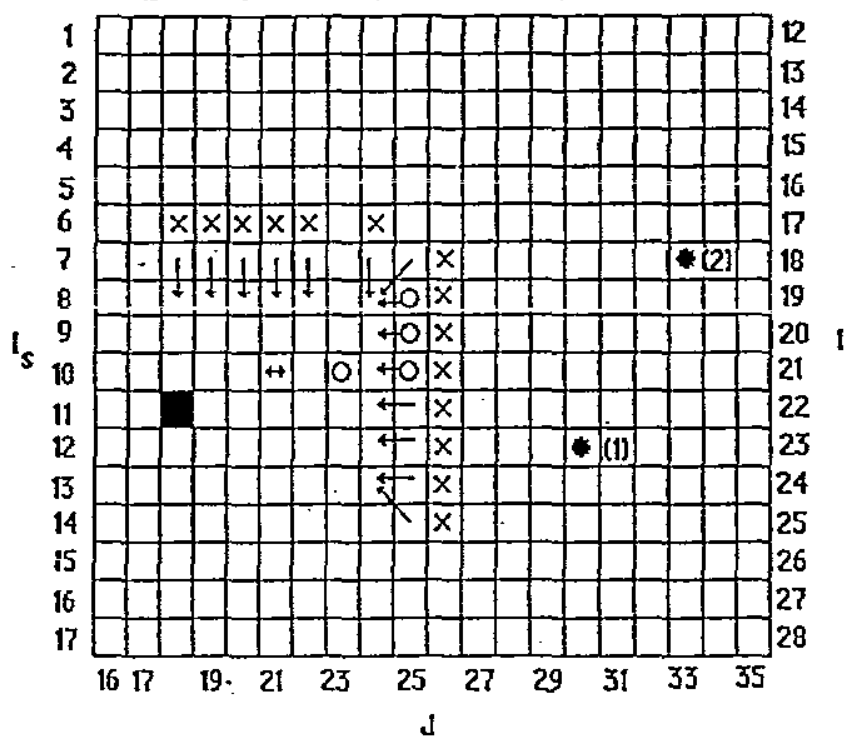

Legend:

6 unmanaged well

(1) byer 1

(2) layer 2

$x$ active managed

injection well

이 active managed extraction weii

contaminant source

$\leftarrow$ tight grad, constr. (heads on same layer)

4 tight grad. constr. thead's on diff. layer] meter

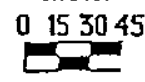

Figure 11 Location of optimal pumping wells and tight head-difference (gradient) constraints for Scenario 3. 
interest. Table 5 illustrates the time needed to address Scenario 1. Included stages use either the discussed simulation models or the PLUMAN code on a $386 \mathrm{PC}$ running at $33 \mathrm{MHz}$ and having 4 MB RAM. Time required for US/REMAX ${ }^{B}$ is comparable to that of PLUMAN, since it uses many of the same solution procedures.

Clearly, the stage of computing influence coefficients, arranging the optimization model, and calculating an optimal strategy is the most computationally intensive. For this scenario and stage, two steps can be distinguished. The first involves computing influence coefficients. The second is model organization and optimization problem solution.

Here, the step of generating influence coefficients requires by far the most time. This results because this act essentially involves one simulation of a modified MODFLOW+STR per potential pumping location. Since there are 31 potential pumping locations, 31 simulations are performed to develop the influence coefficients needed for the response matrix. The more decision variables (potential pumping rates), the more computer time involved in this step.

The step involving model formulation and calculation of the optimal strategy is fairly short. The time needed to perform the optimization is a function of the number of decision variables (potential pumping rates) and state variables (heads or gradients that must be constrained within the optimization model). The larger these numbers, the more time required.

Second, the size of the optimization problem being solved is of interest. For example, the special versions of US/WELLS ${ }^{\mathrm{D}}$ and US/REMAX ${ }^{\mathrm{B}}$ that are released in shortcourses are limited in the number of nonzero values they can have in the optimization formulation. (Even optimization algorithms that are not part of water management models are commonly limited either in the number of nonzeros or in the number of rows and columns in their constraint equations.)

By way of explanation, there is one row in the response matrix per head or gradient constraint equation per time step of constraint. There is one column in the matrix per decision variable. For a steady-state problem, total matrix size is the product of the number of control locations and the number of decision variables. The matrix contains one nonzero coefficient for each potential pumping location-head control location pair (per time step of active constraint).

For the steady-state Scenario 1 , there are $31 \times(22+31)$, or 1643 , nonzeros due to influence coefficients. There are also 31 nonzeros due to the weighting coefficients (even if they are 1 in value) assigned to decision variables in the objective function. Thus, the optimization model formulation for Scenario 1 employs almost 1700 nonzeros. (That of Scenario A using US/WELLS ${ }^{\mathrm{D}}$ includes 919 nonzeros.) This number can be reduced significantly by considering injection in only every other cell on the plume periphery rather than in each cell. For example, if only 12 injection wells were considered, the number of nonzeros would be about $18 \times(22+18)+18$, or 738 . In addition to reducing problem size, this would significantly reduce computational time.

Table 5 . Computer Time Required to Perform Each Activity for Scenario 1

\begin{tabular}{llr}
\hline Step & \multicolumn{1}{c}{ Software used } & Time (min) \\
\hline 1 & MODFLOW +STR (compute nonoptimal head) & 5.0 \\
2 & MOC (predict solute transport in a nonoptimal potent surface) & 35.0 \\
3 & PLUMAN (compute influence coefficients, formulate management model & 150.0 \\
& and determine optimal pumping strategy) & 1.3 \\
4 & MODFLOW+STR (compute transient head response to optimal pumping) & 8.0 \\
5 & MOC (compute head and solute transport response to optimal pumping) & \\
\hline
\end{tabular}


Reducing the number of nonzeros below 1000 is important because that is the upper limit on problem size in the inexpensive "special" versions of US/REMAX ${ }^{\mathrm{B}}$ and US/WELLS ${ }^{\mathrm{D}}$. If problem size increases beyond that, software price increases dramatically. The full professional versions of the software can address problems of virtually unlimited size.

\section{SUMMARY}

Use of simulation/optimization models can significantly aid management of groundwater contamination. It can speed the design process and reduce manpower costs. It can improve the produced remediation designs and reduce remediation costs. It can easily address problems previously considered very difficult.

S/O modeling methods for groundwater flow management have been well established in research literature. Now, generally applicable S/O models are available for use on PCs. The discussed models, US/WELLS ${ }^{\mathrm{D}}$ and US/REMAX ${ }^{\mathrm{B}}$, use linear systems theory, influence coefficients, and superposition. These models can address a wide range of problems. Easy to use, they include all simulation and optimization algorithms needed to compute optimal strategies.

US/WELLS ${ }^{\mathrm{D}}$ and US/REMAX ${ }^{\mathrm{B}}$ are perfectly applicable to linear (confined) aquifer systems and can be applied to nonlinear systems. The former is most appropriate for fairly homogeneous aquifer and stream-aquifer systems. The latter can address complex heterogeneous multilayer stream-aquifer systems.

Increasing use of these PC-based S/O models is anticipated, especially as user-friendly options increase. Even the special versions of these models (released at shortcourses), can solve important real-world problems.

\section{REFERENCES}

1. Peralta, R. C., and Willardson, L. S., Optimizing ground water planning and management, U.S. Committee on Irrigation and Drainage Newsletter, April/June 1992, Denver, Colo., pp. 61-65.

2. Clarke, D., Microcomputer Programs for Groundwater Studies, Elsevier, New York, 1987.

3. Glover, R. E., and Balmer, G. G., River depletion resulting from pumping a well near a river, Trans. AGU, 35(3), (1954).

4. McDonald, M. G., and Harbaugh, A. W., A modular three-dimensional finite-difference groundwater flow model, in Techniques of Water-Resources Investigations, U.S. Geological Survey, 1988, Chapter A1, Book 6.

5. Gorelick, S. M., A review of distributed parameter groundwater management modeling methods, Water Resources Res., 19(2), 305-319 (1983).

6. Morel-Seytoux, H. J., A simple case of conjunctive surface-ground-water management, Ground Water, 13(6) (1975).

7. Verdin, K. L., Morel-Seytoux, H. J., and Illangasekare, T. H., Users Manual for AQUISIM: FORTRAN IV Programs for Discrete Kernel Generation and for Simulation of Isolated Aquifer Behavior in 2 Dimensions, HYDROWAR Program, Colorado State Univ., Fort Collins, Colo., 1981.

8. Heidari, M., Application of linear systems theory and linear programming to groundwater management in Kansas, Water Resources Bull., I8(6), 1003-1013 (1982).

9. Illangasekare, T. H., Morel-Seytoux, H. J., and Verdin, K. L., A technique of reinitialization for efficient simulation of large aquifers using the discrete kernel approach, Water Resources Res., 20(11), 1733-1742 (1984).

10. Danskin,W. R., and Gorelick, S. M., A policy evaluation tool: management of a multisystem using controlled stream recharge, Water Resources Res., 21(11), 1731-1747 (1985).

11. Lefkoff, L. J., and Gorelick, S. M., AQMAN: Linear and Quadratic Programming Matrix Generator Using Two-Dimensional Ground-water Flow Simulation for Aquifer Management Modeling, U.S. Geological Survey Water-Resources Investigations Rep. 87-4061, 1987. 
12. Reichard, E. G., Hydrologic influences on the potential benefits of basinwide groundwater management, Water Resources Res., 23(1), 77-91 (1987).

13. Ward, R. L., and Peralta, R. C., EXEIS-Expert Screening and Optimal Extraction/Injection Pumping Systems for Short-Term Plume Containment, Rep. ESL-TR-87-57, Air Force Engineering and Services Center, Tyndall AFB, Fla., 1990.

14. Willis, R., and Finney, B., Optimal control of nonlinear groundwater hydraulics: theoretical development and numerical experiments, Water Resources Res., 2I(10), 1476-1482 (1985).

15. Aly, A. H., and Peralta, R. C., US/WELLS ${ }^{D}$, Extraction/Injection Well System for Optimal Groundwater Management: User's Manual, Biological and Irrigation Eng. Dept., Utah State Univ., Logan, Utah, 1992.

16. Peralta, R. C., Aly, A. H., Suguino, H. H., Belaineh, G., and Miyojim, M., US/REMAX ${ }^{B}$, Utah State Model for Optimizing Management of Stream-Aquifer Systems Using the Response Matrix Method: User's Manual, Version 1.05, Biological and Irrigation Eng. Dept., Utah State Univ., Logan, Utah, 1992.

17. Prudic, D. E., Documentation of a Computer Program to Simulate Stream-Aquifer Relations Using a Modular, Finite-Difference, Ground-Water Flow Model, U.S. Geological Survey, Open-File rep. 88-729, 1989.

18. Suguino, H., and Peralta, R. C., PLUMAN: A Decision Support System for Optimal Groundwater Contaminant Plume Management: User's Manual, Version 1.0, Software Eng. Div., Dept. Biological and Irrigation Eng., Utah State Univ., Logan, Utah, 1992.

19. Konikow, L. F., and Bredehoeft, J. D., Computer model of two-dimensional solute transport and dispersion in ground water, in Techniques of Water Resources Investigations, USGS, Washington, D.C., 1984, Book 7, Chapter C2.

20. Suguino, H., A decision support system for optimal groundwater contaminant plume management, Ph.D. dissertation, Dept. Agricultural and Irrigation Eng., Utah State Univ., Logan, Utah, 1992.

21. Todd, D. K., Groundwater Hydrology, Wiley, New York, 1980.

\section{ADDITIONAL READING}

Colarullo, S. J., Heidari, M., and Maddock, T., III (1984). Identification of an optimal groundwater management strategy in a contaminated aquifer, Water Resources Bull., 20(5), 747-760.

Gharbi, A. (1991). Optimal groundwater quantity and quality management with application to the Salt Lake Valley, Ph.D. Dissertation, Dept. Agricultural and Irrigation Eng., Utah State Univ., Logan, Utah.

Peralta, R. C., Killian, P. J., Yazdanian, A., and Kumar, V. (1989). SSTAR Users Manual; Rep. IIC-89/3, International Irrigation Center Utah State Univ., Logan, Utah. 
JOBNAME: No Job Name PAGE: 22 SESS: 19 OUTPUT: Tue Aug 24 01:35:06 1993

/xycomp/ - main -/booksm-z/marcel/2554engin/ch29 